University of Nebraska - Lincoln

DigitalCommons@University of Nebraska - Lincoln

2011

Structure of $\mathrm{n}$-heptane/air triple flames in partially-premixed mixing layers

J. Prager

Sandia National Laboratories, Livermore, CA

H. N. Najm

Sandia National Laboratories, Livermore, CA

M. Valorani

Sapienza University, Rome, Italy

D.A. Goussis

National Technical University of Athens, Athens, Greece

Follow this and additional works at: https://digitalcommons.unl.edu/usdoepub

Part of the Bioresource and Agricultural Engineering Commons

Prager, J.; Najm, H. N.; Valorani, M.; and Goussis, D.A., "Structure of n-heptane/air triple flames in partiallypremixed mixing layers" (2011). US Department of Energy Publications. 128.

https://digitalcommons.unl.edu/usdoepub/128

This Article is brought to you for free and open access by the U.S. Department of Energy at DigitalCommons@University of Nebraska - Lincoln. It has been accepted for inclusion in US Department of Energy Publications by an authorized administrator of DigitalCommons@University of Nebraska - Lincoln. 


\title{
Structure of $n$-heptane/air triple flames in partially-premixed mixing layers
}

\author{
J. Prager ${ }^{\mathrm{a}, *}$, H.N. Najm ${ }^{\mathrm{a}}$, M. Valorani ${ }^{\mathrm{b}}$, D.A. Goussis ${ }^{\mathrm{c}}$ \\ a Sandia National Laboratories, Livermore, CA 94551-0969, USA \\ ${ }^{\mathrm{b}}$ Sapienza University, Rome, Italy \\ ${ }^{\mathrm{c}}$ National Technical University of Athens, Athens, Greece
}

\section{A R T I C L E I N F O}

\section{Article history:}

Received 25 October 2010

Received in revised form 25 February 2011

Accepted 29 March 2011

Available online 18 April 2011

\section{Keywords:}

Edge flames

Triple flames

n-heptane

\begin{abstract}
A B S T R A C T
Results of a detailed numerical analysis of an $n$-heptane/air edge flame are presented. The equations of a low-Mach number reacting flow are solved in a two-dimensional domain using detailed models for species transport and chemical reactions. The reaction mechanism involves 560 species and 2538 reversible reactions. We consider an edge flame that is established in a mixing layer with a uniform velocity field. The mixing layer spans the equivalence ratios between pure air and 3.5. The detailed model enables us to analyze the chemical structure of the $n$-heptane edge flame. We identify major species profiles, discuss reactions causing the heat-release, and exploit Computational Singular Perturbation (CSP) to discuss the main fuel-consumption pathways and the structure of explosive modes in the edge flame. This analysis is performed for several regions in the edge flame to discuss the different processes at work in the premixed branches and the trailing diffusion flame. We compare different cuts through the 2D edge flame to canonical 1D premixed and diffusion flames. We also analyze the accuracy of a skeletal mechanism which was previously developed using CSP from homogeneous ignition calculations of $n$-heptane and show that a significant reduction in size of the mechanism can be achieved without a significant decrease in accuracy of the edge flame computation. This skeletal mechanism is then used to study the effects of increasing the equivalence ratio in the partially-premixed fuel stream.
\end{abstract}

(c) 2011 The Combustion Institute. Published by Elsevier Inc. All rights reserved.

\section{Introduction}

Edge flames are important flame structures occurring in a large variety of premixed and non-premixed combustion systems. They exist in spatial regions in which a premixed, combustible mixture has been established and propagate in the direction of stoichiometric mixture composition. Edge flames consist of a premixed flame front and a trailing diffusion flame. A special case of an edge flame is the triple or tribrachial flame in which the flame front is made up of distinct lean and rich premixed branches. Depending on the type of fuel and the exact mixture composition, the lean or rich branches can be degenerate.

In the laminar flame context, edge flames are found in jet flames and play an important role in the lift-off height of lifted jet flames. Edge flames can also be created in opposed-jet burners $[1,2]$. In turbulent combustion, edge flames can be found as well and are of importance, for instance, for the development of flame holes. For an extensive review see the works of Buckmaster or Chung $[3,4]$.

The computational resources that are available today allow the study of the chemical structure of edge flames for complex

\footnotetext{
* Corresponding author.

E-mail address: jprager@sandia.gov (J. Prager).
}

hydrocarbon fuels in full detail. These calculations unveil information about processes important for the propagation speed, such as differential diffusion effects, but also enable us to study the different reaction pathways active in different regions of the flame structure and, even more importantly, their interactions. As a canonical flame structure, edge flames share features of premixed propagating flames but also diffusion flames. The details about the interplay between these two different combustion modes in edge flames of complex fuels, their dependence on fuel and flow parameters, and their parametrization are still an active field of research [4]. Moreover, computations of single edge flames using a variety of fuels, mixture fraction profiles, and flow fields lead to important insights on their properties that are necessary to gain a deeper understanding of more complex combustion phenomena such as lifted laminar jet flames or turbulent combustion, e.g. [5-7].

Over the past 10 years, great effort was put into numerical simulations of edge flames focusing on their structure using detailed reaction models. Starting from studies of hydrogen and methanol flames in mixing layers with uniform velocity fields $[6,8]$ to burner-scale laminar edge flames of methane [1,2,7,9-15], ethane/ethylene/acetylene/propane [16] and heptane, conducted recently [17]. Aspects that have been studied numerically are fuel-consumption pathways, sources of heat-release, $\mathrm{NO}_{x}$ chemistry, and propagation properties and their dependence on flame curvature, 
flame strain, differential diffusion and gravity effects. In our recent work on methane/air edge flames we studied $\mathrm{NO}_{x}$ production pathways and used Computational Singular Perturbation (CSP) theory to analyze the chemical structure and timescales found in these flames [18,19].

In this paper, we present results of a numerical analysis of an $n$ heptane/air edge flame burning into a mixing layer of uniform velocity using a detailed chemical model of 560 species and 2538 reversible reactions. There are very few detailed studies of edge flames for $n$-heptane fuel. Katta et al. [17] showed results of calculations in two spatial dimensions of opposing-jet and co-flow configurations using three chemical kinetics models involving 52, 160, and 197 species. This work focused on the differences between the three reaction mechanisms and their applicability for premixed and non-premixed flame calculations. In contrast, we put our emphasis on the detailed description and analysis of the spatially resolved tip of an edge flame that can be found in these opposing-jet and co-flow configurations. There are also studies of 1D opposed-jet configurations using a partially-premixed heptane fuel jet $[20,21]$. This configuration allows the study of the chemistry and interactions of a symbiotic premixed/diffusion flame, but these are only qualitatively similar to edge flames in $2 \mathrm{D}$ or $3 \mathrm{D}$ configurations.

In the following, we will first introduce the numerical scheme and computational setup and discuss efficiency issues of this large-scale computation. Then we will give a short introduction into Computational Singular Perturbation (CSP) theory which we use to analyze the fuel-consumption network and explosive modes of the flame. Afterward, we analyze the flame structure of the edge flame, using reaction-flow analysis for the first steps of the fuel consumption and heat-release. A comparison with one-dimensional flames follows to find similarities to cuts through the edge flame and discuss the interactions found in the two-dimensional edge flame. Finally, we will discuss the accuracy of a skeletal mechanism and exploit it for a parametric study in which we increase the equivalence ratio in the fuel stream.

\section{Numerical model}

The numerical scheme is based on the time-dependent lowMach number approximation of reactive flows. Buoyancy and radiation effects are neglected for this small-scale study. We use the DRFM ('dipole reduced formalism') transport model in the mixture-average formulation [22] and a detailed reaction mechanism of elementary reactions. A detailed description of the numerical procedure can be found elsewhere [23-25]. We use the detailed $n$-heptane reaction mechanism of Curran et al. [26,27] which consists of 560 species and 2538 reversible reactions. This reaction mechanism has been developed to model the oxidation of $n$-heptane in flow reactors, shock tubes, and rapid compression machines over a wide range of equivalence ratio, pressure, and temperature. It includes a detailed description of high- and lowtemperature chemistry. The low-temperature chemistry proceeds through peroxy- and hydroperoxy-alkyl radicals to ketohydroperoxide species.

The computational domain is a two-dimensional square of $4 \mathrm{~mm}$ size using 512 uniformly distributed grid points in both dimensions. This leads to a spatial resolution of $7.8 \mu \mathrm{m}$. The lower boundary is the inflow boundary. We chose a spatially varying mixture composition at $400 \mathrm{~K}, 1 \mathrm{~atm}$ and uniform inflow velocity of $71.7 \mathrm{~cm} / \mathrm{s}$ as inflow condition. This velocity is the speed of a stoichiometric $n$-heptane/air flame obtained with the reaction mechanism and transport data at the same conditions. The mixture composition varies from pure air on the left side of the domain to a mixture of equivalence ratio of $\phi=3.5$ on the right-hand side of the domain, see Fig. 1. The upper boundary is implemented as an outflow boundary. At the left and right sides of the domain, periodic-symmetric boundary conditions are applied.

The computations were initialized by establishing a flat horizontal flame front on the grid and then gradually changing the mixture composition at the inflow boundary. The flow is computed long enough to achieve a quasi-stationary solution of the edge flame, i.e. a steadily propagating edge flame without changes in its structure. It would be computationally too costly to follow this procedure using the most detailed mechanism of 560 species. Instead, we do these first steps using a previously developed skeletal mechanism for $n$-heptane/air combustion containing 66 species (M66) $[28,29]$. Afterward we continue the calculations using a larger mechanism of 139 and then 560 species by adding the new species with zero mole fraction. The calculations are run long enough until all transients are vanished and a steadily propagating flame is obtained. Starting from a stable solution for 139 species we propagated the solution for approximately $1.1 \mathrm{~ms}$ to obtain the final solution of 560 species.

We use the definition of mixture fraction $\xi$ as proposed by Bilger [30]:

$Z=\frac{1}{7} \frac{Z_{\mathrm{C}}}{W_{\mathrm{C}}}+\frac{1}{16} \frac{Z_{\mathrm{H}}}{W_{\mathrm{H}}}-\frac{1}{11} \frac{Z_{\mathrm{O}}}{W_{\mathrm{O}}}$

$\xi=\frac{Z-Z^{\mathrm{ox}}}{Z^{\mathrm{f}}-Z^{\mathrm{ox}}}$

The subscripts of $Z$ denote the elements $\mathrm{C}, \mathrm{H}, \mathrm{O}$. The mixture fraction is normalized by using $Z$ of the fuel $Z^{f}$ and oxidizer $Z^{\text {ox }}$ streams. Using this definition, the mixture fraction at the inflow was chosen using a hyperbolic tangent profile:

$\xi(x)=\frac{1}{2} \tanh (a x-b)+\frac{1}{2} \quad 0 \leqslant x \leqslant L_{x}$

The parameters $a, b$, and the domain length $L_{x}$ can be found in Table 1 . They are chosen in a way that there is pure air on the left boundary of the domain and a premixed fuel rich $n$-heptane/air mixture of equivalence ratio 3.5 on the right side, see Flame A in Fig. 1. A second case which makes use of the smallest skeletal mechanism M66 will also be discussed. We use this smaller mechanism to study the

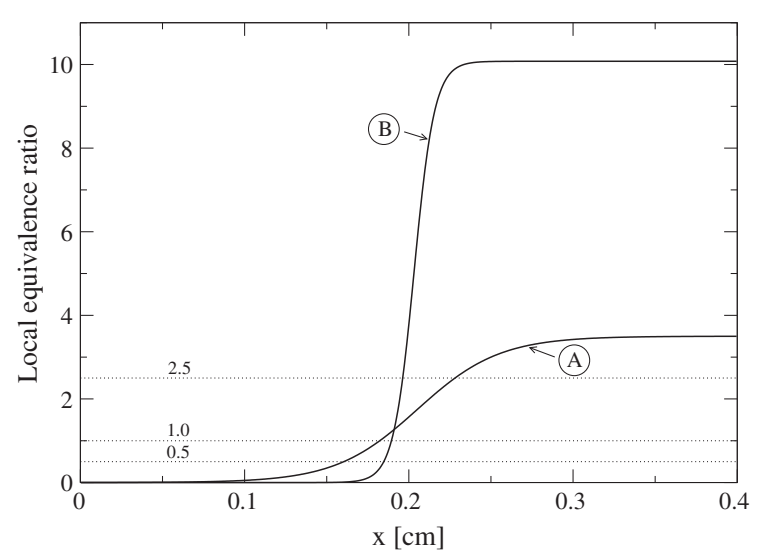

Fig. 1. Profiles of local equivalence ratios at the inflow boundary for flame A and flame B.

Table 1

Inflow parameters and domain sizes of the two triple-flame calculations, see Eq. (1).

\begin{tabular}{llrllll}
\hline Flame & $\phi_{o}$ & \multicolumn{1}{c}{$\phi_{f}$} & $a\left(\mathrm{~mm}^{-1}\right)$ & $b$ & $L_{x}(\mathrm{~mm})$ & $L_{y}(\mathrm{~mm})$ \\
\hline A & 0.0 & 3.5 & 2 & 4 & 4 & 4 \\
B & 0.0 & 10.1 & 8 & 16 & 4 & 4 \\
\hline
\end{tabular}


effect of increasing the equivalence ratio of the fuel stream in the inflow from 3.5 to 10, see Flame B in Fig. 1 and Table 1.

\section{Numerical efficiency}

The calculations using the complete reaction mechanism were performed on a CRAY XT4 massively parallel computer [31]. Our software uses MPI to communicate between the nodes of the machine and on each node we use OpenMP to utilize their quadcore architecture. The computational domain is partitioned into rectangular sub-domains. The main computational load is due to the integration of the stiff chemical source terms and depends on the mixture composition and temperature at each grid point. To achieve load balance between the nodes we decompose the domain in a way that each node has the same computational load. This leads to small partitions in regions of the burning flame. We test every tenth time step if a re-partitioning became necessary. A typical partitioning is shown in Fig. 2. The computation using the full detailed reaction mechanism of 560 species presented in this paper involved 484 nodes (1936 CPU-cores total) and required approximately $55 \mathrm{~h}$.

Table 2 lists some timing results for the three reaction mechanisms used in this work. We find an approximately quadratic scaling with the number of species. The largest outlier is the M560 calculation using the LINPACK library [32] to solve the linear system that results from using DVODE [33] as the stiff-ODE solver. By replacing it with the LAPACK library [34] we find consistent computational performance. LAPACK is known for its better conformity to modern computational hardware with respect to cache utilization [34]. This seems to be the case here as well. Using the vendor-optimized LAPACK library yields an additional and significant performance gain. Another significant gain was achieved by using an analytical Jacobian instead of a numerical approximation. Finally, the mixed MPI/OpenMP parallelism showed advantages over a pure MPI implementation. Overall, the wall-clock times in Table 2 also show clearly the requirement to use a massively parallel computer if large detailed reaction mechanisms are to be considered.

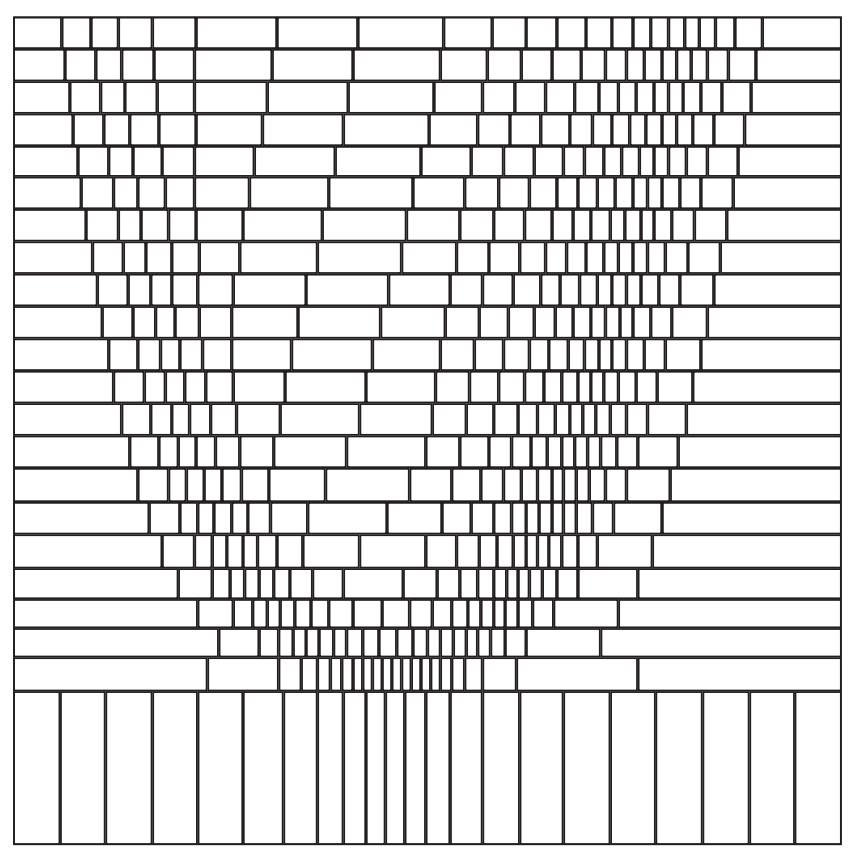

Fig. 2. Partitioning of the computational domain to achieve load balance. 484 nodes are used.
Table 2

Wall clock time in minutes for a 500 ns timestep using the three skeletal mechanisms. Twenty-five nodes with four cores each are used on Franklin of NERSC [31]. If not noted otherwise, the mixed MPI/OpenMP parallelism is utilized and an analytical Jacobian is provided.

\begin{tabular}{llll}
\hline & M560 & M139 & M66 \\
\hline LINPACK & 198 & 1.31 & 0.33 \\
LAPACK & 53 & 1.50 & 0.35 \\
LAPACK optimized & 22 & 0.93 & 0.28 \\
LAPACK optimized, pure MPI & 25 & 1.12 & 0.37 \\
LAPACK optimized, numerical Jacobian & 37 & 2.02 & 0.55 \\
\hline
\end{tabular}

\section{Computational Singular Perturbation (CSP)}

In this paper, we use CSP to construct a graph of the network of important fuel-consumption reactions within an edge flame structure. We do this by the automated procedure which produces reduced (skeletal) reaction mechanisms as described in earlier work [35,29].

It is by now well established that the fastest time scales developing in the dynamics of flames are due to some components of the chemical kinetics mechanism. These time scales are of dissipative character and are associated with the existence of large eigenvalues of the Jacobian of the system, which have dominant and negative real part and are much larger in magnitude than the rest of the eigenvalues. Such features are essential for the development of a low dimensional surface in phase space, defined as a slow invariant manifold (SIM) [36,37]. All neighboring trajectories are attracted to the SIM under the influence of the fast dissipative time scales, while on the SIM, the solution evolves according to the slow time scales.

The slow evolution along the SIM is governed by a simplified system of equations, which is free of the fast dissipative time scales. The simplified system is produced (i) by first decomposing the tangent space at any point along the system trajectory into the fast and slow subspaces, and (ii) by projecting the vector field onto these two subspaces $[38,39]$. The fast and slow subspaces are spanned by the fast/slow CSP vectors, respectively, which can be approximated with CSP via an iterative algorithm [38,40-43]. Therefore, both the SIM and the simplified system that governs the slow evolution on the SIM can be algorithmically constructed. This feature of CSP allows for both an efficient solution of the original stiff system of governing equations and the acquisition of a deep physical understanding on the evolution of the system and on the role of each component in the mathematical model.

In particular, the development of the SIM signifies the establishment of various equilibria among the physical process in the mathematical model, i.e. chemical kinetics and diffusion [44,45]. CSP allows for the identification of the processes that participate in the formation of the SIM (under the influence of the fast dissipative time scales) and those that participate in the simplified system that governs the evolution on the SIM (according to the slow time scales) $[19,45,46]$. The slow time scales that characterize the evolution along the SIM can be either dissipative or explosive. The former related to activities towards further equilibrations and the later related to activities away from them [47-50].

The evolution equations for the system's state vector $\boldsymbol{w}$ (species mass fractions and temperature) can be written as:

$\frac{\partial \boldsymbol{w}}{\partial t}=\boldsymbol{f}=\boldsymbol{L}(\boldsymbol{w})+\sum_{k=1}^{R} \boldsymbol{S}_{k} R^{k}(\boldsymbol{w})$,

where $\boldsymbol{L}$ represents the convective-diffusive terms and $\boldsymbol{S}_{k}$ and $R^{k}$ are the generalized stoichiometric vector and the generalized rate of progress of the $k$-th reaction, respectively. CSP provides a set of 
basis vectors and co-vectors $\left\{\boldsymbol{a}_{i}, \boldsymbol{b}^{i}\right\}_{i=1}^{N}$ to decompose the right-hand side of Eq. (2) into a fast $\boldsymbol{f}_{r}(\boldsymbol{w})$ and a slow $\boldsymbol{f}_{s}(\boldsymbol{w})$ contribution:

$\boldsymbol{f}=\boldsymbol{f}_{r}(\boldsymbol{w})+\boldsymbol{f}_{s}(\boldsymbol{w})=\sum_{r=1}^{M} \boldsymbol{a}_{r} h^{r}+\sum_{s=M+1}^{N} \boldsymbol{a}_{s} h^{s}$,

with the mode amplitudes $h^{i}=\boldsymbol{b}^{i} \cdot \boldsymbol{f}$. As a leading-order approximation to these basis vectors we use the eigenvectors of the Jacobian of the chemical source term [43]. The $N$ modes are ordered with increasing time scale, the first $M$ of which are considered exhausted. $M$ is the largest number of modes satisfying

$\left|\tau^{M+1} \sum_{r=1}^{M} a_{r}^{i} h^{r}\right|<w_{\text {error }}^{i}$

for all components $i$ of the error vector $\boldsymbol{w}_{\text {error. }}$ Here, $\tau^{M+1}$ is the time scale of mode $M+1$, i.e. the fastest of the slow time scales. The value of $M$ varies with the location in the flame. In this work, we use an error vector based on absolute $\epsilon_{\mathrm{abs}}=10^{-3}$ and relative $\epsilon_{\mathrm{rel}}=10^{-13}$ tolerances:

$w_{\mathrm{error}}^{i}=\epsilon_{\mathrm{rel}} \cdot w^{i}+\epsilon_{\mathrm{abs}}$.

In the analysis, we will use the importance indices $I_{k}^{i}$ that CSP provides. They are a measure of the importance of a reaction $k$ for the time evolution of species $i$. We distinguish between importance indices projected in the fast ' $r$ ' and slow ' $s$ ' subspaces:

$$
\begin{aligned}
I_{k, r}^{i} & =\frac{\sum_{j=1}^{M} a_{j}^{i}\left(\boldsymbol{b}^{j} \cdot \boldsymbol{S}_{k}\right) R^{k}}{\sum_{k^{\prime}=1}^{N}\left|\sum_{j=1}^{M} a_{j}^{i}\left(b_{k^{\prime}}^{j} L_{k^{\prime}}\right)\right|+\sum_{k^{\prime}=1}^{R}\left|\sum_{j=1}^{M} a_{j}^{i}\left(\boldsymbol{b}^{j} \cdot \boldsymbol{S}_{k^{\prime}}\right) R^{k^{\prime}}\right|} \\
I_{k, s}^{i} & =\frac{\sum_{j=M+1}^{N} a_{j}^{i}\left(\boldsymbol{b}^{j} \cdot \boldsymbol{S}_{k}\right) R^{k}}{\sum_{k^{\prime}=1}^{N}\left|\sum_{j=M+1}^{N} a_{j}^{i}\left(b_{k^{\prime}}^{j} L_{k^{\prime}}\right)\right|+\sum_{k^{\prime}=1}^{R}\left|\sum_{j=M+1}^{N} a_{j}^{i}\left(\boldsymbol{b}^{j} \cdot \boldsymbol{S}_{k^{\prime}}\right) R^{k^{\prime}}\right|} .
\end{aligned}
$$

We use the importance indices to construct a graph of the network of important fuel-consumption reactions, employing the model simplification algorithm in $[35,29]$. The procedure requires a database of system states, computed with the detailed chemical mechanism, and a set of target species of interest. For each state vector in the database, the algorithm proceeds as follows. It includes reactions, involving the set of included species, that have a normalized importance index above a selected threshold $\alpha$ :

$\left|\frac{I_{k, s \mid r}^{i}}{\max _{k}\left(I_{k, s \mid r}^{i}\right)}\right|>\alpha$

Slow importance indices are examined for all included species. On the other hand, fast importance indices are inspected only for CSP radicals, namely those species that are most associated with the $M$ fast modes. All species participating in the included reactions are added to the list of target species, and the procedure is repeated iteratively until no new species are found. The union of all important species and reactions for all state vectors in the database provides the sought-after skeletal mechanism. In the present context, we start with the target species $n-\mathrm{C}_{7} \mathrm{H}_{16}$, and the algorithm is applied to all locations in a selected region of the edge flame. We plot the reaction network by selecting only those species in the skeletal mechanism which contain at least one carbon atom. The value of the threshold parameter for importance indices $\alpha$ is chosen large enough to select only the main reactions, but small enough to provide a reaction network which connects the fuel to the final product $\mathrm{CO}_{2}$. The resulting diagram of the reaction network is a skeletal reaction diagram outlining important pathways. Note that, since the slow and fast subspaces are studied separately by the algorithm, as decoupled using CSP, fast reactions do not mask important slow reactions.
We will also use CSP to analyze explosive modes in the triple flame. In analyzing the eigenvalues of the Jacobian of the chemical source term there can be eigenvalues $\lambda_{\exp }$ with a positive real part. These eigenvalues belong to modes with divergent, explosive behavior. Their time scale is the inverse of the real part of its eigenvalue: $\tau_{\exp }=1 / \mathfrak{R}\left(\lambda_{\exp }\right)$. We can analyze the explosive mode by the CSP pointer $Q_{k}^{\exp }$ of a species $k$ with respect to the explosive mode, represented by its eigenvector pair $\boldsymbol{a}_{\exp }$ and $\boldsymbol{b}^{\exp }$ :

$Q_{k}^{\exp }=a_{\exp }^{k} \cdot b_{k}^{\exp }$.

The value of this CSP pointer measures the projection of eigenvector $\boldsymbol{a}_{\text {exp }}$ onto the direction of species $k$ in composition space. Finally, we will consider the participation indices $P_{l}^{\exp }$ of a transport process $l$ and $P_{k}^{\exp }$ of a chemical reaction $k$ in the explosive mode:

$$
\begin{aligned}
& P_{l}^{\exp }=\frac{b_{l}^{\exp } \cdot L^{l}}{\sum_{l^{\prime}}\left|b_{l^{\prime}}^{\exp } \cdot L^{I^{\prime}}\right|+\sum_{k^{\prime}}\left|\left(\boldsymbol{b}^{\exp } \cdot \boldsymbol{S}_{k^{\prime}}\right) R^{k^{\prime}}\right|} \\
& P_{k}^{\exp }=\frac{\left(\boldsymbol{b}^{\exp } \cdot \boldsymbol{S}_{k}\right) R^{k}}{\sum_{l^{\prime}}\left|b_{l^{\prime}}^{\exp } \cdot L^{I^{\prime}}\right|+\sum_{k^{\prime}}\left|\left(\boldsymbol{b}^{\exp } \cdot \boldsymbol{S}_{k^{\prime}}\right) R^{k^{\prime}}\right|} .
\end{aligned}
$$

These participation indices determine the contributions of transport processes and reactions to the mode amplitude $h^{\exp }$ associated with an explosive mode.

\section{Results}

First we will describe the general structure of an $n$-heptane edge flame (flame A) obtained using the detailed reaction mechanism M560, and discuss the main fuel-consumption pathways and reactions that cause the heat-release. We will also discuss similarities to one-dimensional premixed and diffusion flames. In the second part, we will assess the accuracy of the skeletal mechanism M66 for computations of the edge-flame configuration. This skeletal mechanism was derived from a database of homogeneous ignition calculations covering a range of stoichiometries $(\phi=$ $\{0.5,1.0,2.0\})$ and initial temperatures $(T=\{1000 \mathrm{~K}, 1250 \mathrm{~K}\})$ [28]. Finally, having established the accuracy of M66, we present a parametric study by varying the amount of fuel in the fuel-rich premixed stream and the thickness of the mixing layer.

\subsection{Flame structure}

The mole fractions of the fuel and $\mathrm{O}_{2}$ are shown in Fig. 3. The outline of the edge flame is clearly visible, the fuel is completely consumed inside the edge flame while oxygen persists at a mole fraction of approximately $0.1 \%$. The streamlines show the divergence effect of the flow field caused by the heat-release in the edge flame [5]. Diffusion processes do not significantly influence the species profiles of the inflow stream prior to the edge flame because of the short time and length scales of the computation shown here. The divergence effect leads to a spatially wider fuel distribution, effectively reducing the gradient of fuel concentration ahead of the edge flame. The temperature isolines are qualitatively very similar to the contours of the $\mathrm{O}_{2}$ mole fraction and represent the shape of the edge flame well.

Figures 4 and 5 show contour lines of the main carbon-containing species found in the flame. These plots show the $10 \%$-isolines of the species mole fractions. The values of the mole-fraction isolines are also shown. The fuel, $\mathrm{CO}$, and $\mathrm{CO}_{2}$ are the three species with largest mole fractions since they are the initial carbon-containing species and the main combustion products. The second most abundant species is $\mathrm{C}_{2} \mathrm{H}_{4}$ which is found mostly on the rich side of the flame but also in the lean branch and at the tip of the edge flame. The next layer consists of $\mathrm{C}_{2} \mathrm{H}_{2}$ which is found mostly in the rich branch behind $\mathrm{C}_{2} \mathrm{H}_{4} \cdot \mathrm{CH}_{4}$ and $\mathrm{C}_{3} \mathrm{H}_{6}$ are the next most abundant species but their mole fractions are significantly smaller. 

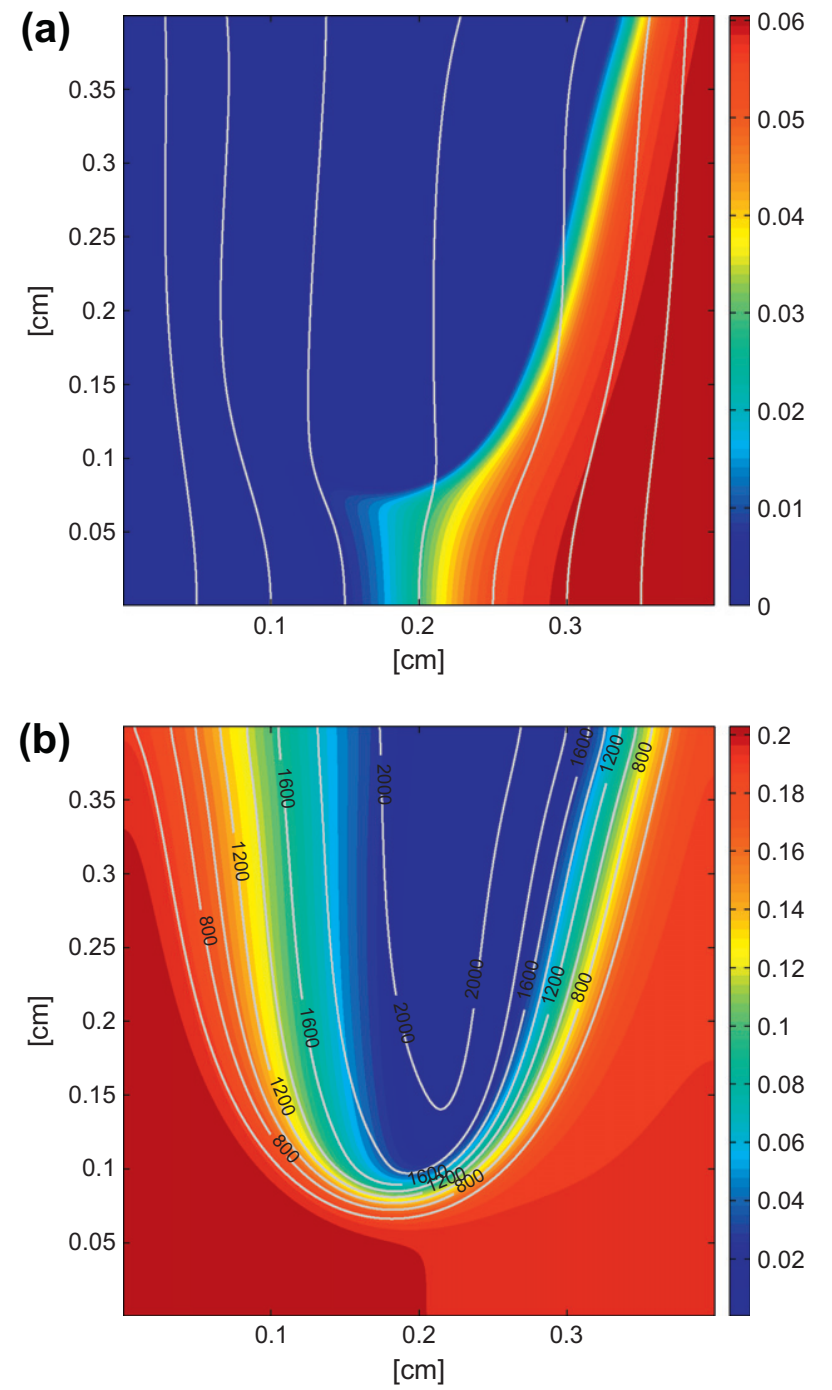

Fig. 3. Contour plots of the (a) $n-\mathrm{C}_{7} \mathrm{H}_{16}$ and (b) $\mathrm{O}_{2}$ mole fractions. Velocity streamlines and isolines of the temperature field are shown as well. The temperature isolines span the range between $600 \mathrm{~K}$ and $2000 \mathrm{~K}$ in $200 \mathrm{~K}$ increments.

\subsubsection{Heat-release rate}

The heat-release rate field in the edge flame is shown in Fig. 6. The main energy release is found in the flame tip slightly on the rich side from the stoichiometric mixture fraction line. The heatrelease continues along the lean and rich branches as well, albeit at a slower rate. Some additional structures can be seen in-between the branches. However, this heat-release rate caused by the trailing diffusion flame is much smaller than the heat-release rate in the premixed regions of the triple flame and not clearly visible in this figure. We find heat-release rates of up to $400 \mathrm{cal} / \mathrm{cm}^{3} \mathrm{~s}$ in the lean branch outside the isocontour of mixture fraction that corresponds to an equivalence ratio of 0.5 . This shows that there is a significant heat-release rate in a mixture close to the lean flammability limit, indicating the importance of interactions between the different reaction zones in a triple flame. For comparison, the maximum heat-release rate of an adiabatic laminar $n$-heptane/air flame of equivalence ratio $\phi=0.4$ and $400 \mathrm{~K}$ unburnt gas temperature was found to be $\approx 40 \mathrm{cal} / \mathrm{cm}^{3} \mathrm{~s}$ [51]. Similar findings were reported by Briones et al. in the case of a methane-air triple flame $[2,13]$.

We want to analyze the contributions of specific chemical reactions to the heat-release rate for two different slices through the

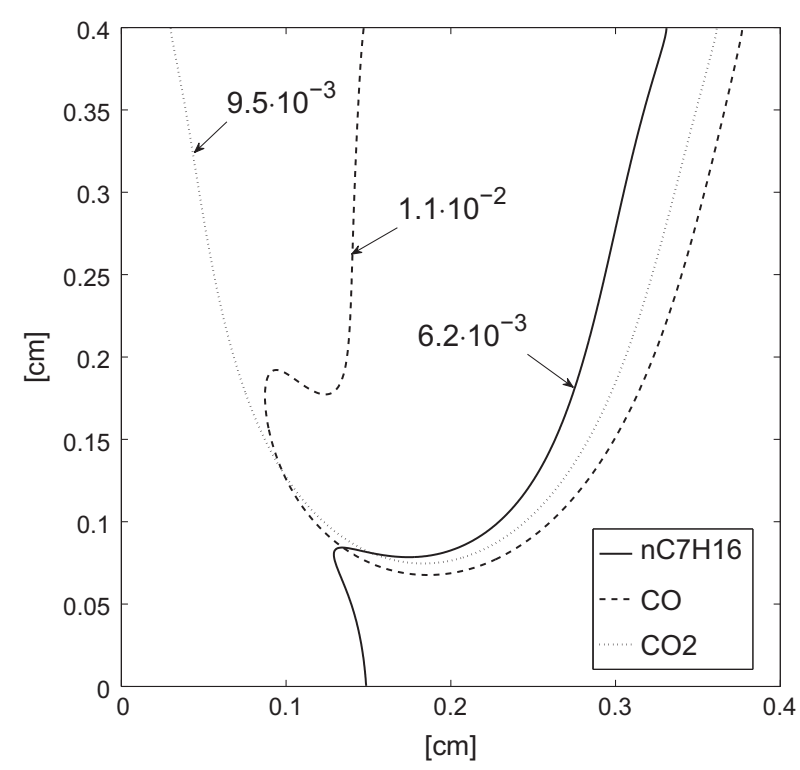

Fig. 4. The $10 \%$ mole-fraction isocontours of the main carbon-containing species $n-\mathrm{C}_{7} \mathrm{H}_{16}, \mathrm{CO}$, and $\mathrm{CO}_{2}$ are shown. The values of the isolines are also provided.

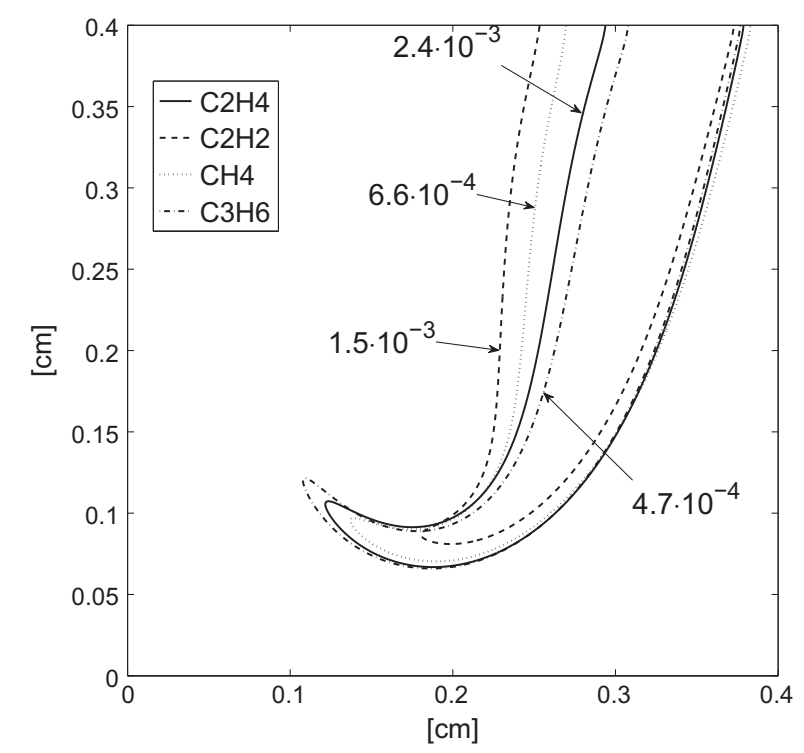

Fig. 5. The $10 \%$ mole-fraction isocontours of the second most abundant, carboncontaining species are shown. The values of the isolines are given to show the relative abundance of the species, i.e. the following order: $\mathrm{C}_{2} \mathrm{H}_{4}>\mathrm{C}_{2} \mathrm{H}_{2}>\mathrm{CH}_{4}, \mathrm{C}_{3} \mathrm{H}_{6}$.

triple flame. CSP offers importance indices for the temperature evolution, and we confirmed for the two slices that these importance indices point qualitatively to the same significant reactions as the direct analysis of heat-release rates.

The first slice is a vertical cut along $x=0.182 \mathrm{~cm}$, see the heatrelease rate in Fig. 7. In this figure we show the total heat-release rate and the sum of all positive and negative contributions separately. The location is chosen because it coincides with the stoichiometric mixture composition at the inflow and cuts approximately through the region with largest heat-release rate. For comparison, we also plot the total heat-release rate of the corresponding premixed flame using the PREMIX tool of CHEMKIN [52]. A stoichiometric mixture at $400 \mathrm{~K}$ unburnt gas temperature is used. The profile is spatially shifted so that the maxima of both curves overlap. We find a single peak of the same width in both cases but the 


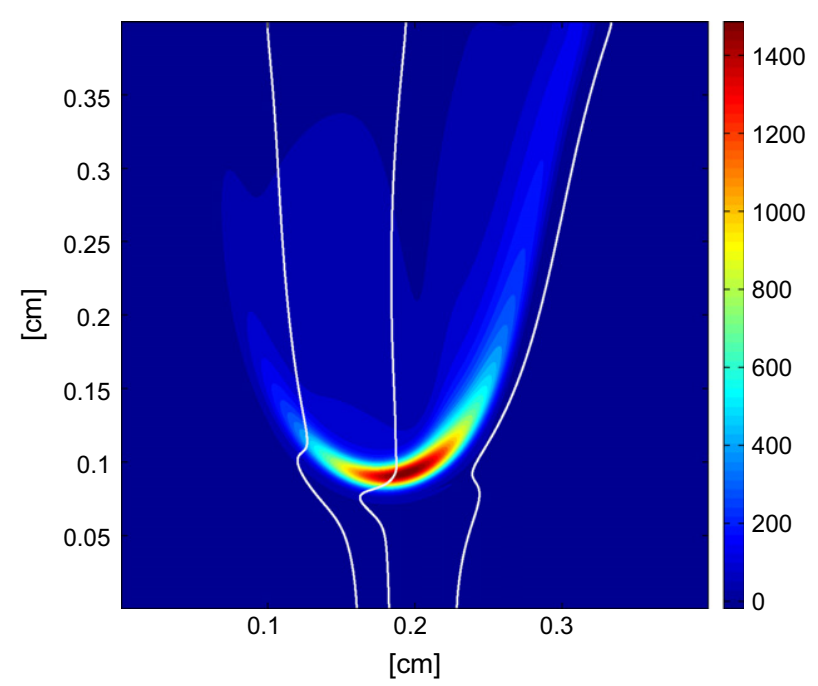

Fig. 6. Heat-release rate $\left[\mathrm{cal} / \mathrm{cm}^{3} \mathrm{~s}\right]$ for M560. Three isolines of mixture fraction are shown as well, corresponding to the stoichiometries $0.5,1.0$, and 2.5 at the inflow.

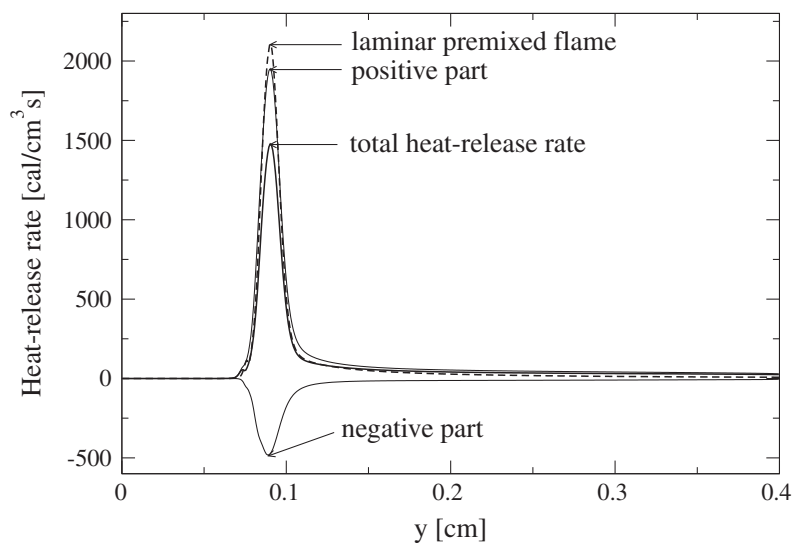

Fig. 7. Heat-release rate along a vertical slice through the triple flame at $x=0.182 \mathrm{~cm}$. In addition to the total heat-release rate its positive and negative components are shown as well. This slice is along the stoichiometric mixture composition at the inflow. The heat-release profile of the corresponding stoichiometric, premixed flame is shown for comparison.

maximum heat-release rate is ca. $42 \%$ larger for the premixed flame. The same trend was found for methane/air triple flames and attributed to lateral heat transport and flame stretch in triple flames [13]. The analysis of the total heat-release rate shows that many reactions contribute and that the main reactions are the same for the cut through the triple flame and the premixed flame. The two most significant ones in the main reaction zone are:

$$
\begin{aligned}
\mathrm{CH}_{3}+\mathrm{O} & \rightarrow \mathrm{CH}_{2} \mathrm{O}+\mathrm{H} \quad(6.8 \%) \\
\mathrm{CH}_{2}(\mathrm{~s})+\mathrm{O}_{2} & \rightarrow \mathrm{CO}+\mathrm{OH}+\mathrm{H} \quad(3.1 \%)
\end{aligned}
$$

The numbers behind the reactions are the percentages of their contributions to the total positive heat-release rate integrated over the whole region. The residual heat-release rate downstream of the main peak is dominated by reactions involving $\mathrm{H}, \mathrm{OH}, \mathrm{H}_{2}$ which produce $\mathrm{H}_{2} \mathrm{O}$ and by the conversion of $\mathrm{CO}$ to $\mathrm{CO}_{2}$.

The second slice is a horizontal cut through the flame at $y=0.3 \mathrm{~cm}$, shown in Fig. 8. Again, we show the total heat-release rate and the sum of all positive and negative contributions separately. Considering the total heat-release rate we find a small maximum on the lean side (region 1 ), a broad plateau between the branches (region 2), a small peak behind the rich premixed branch (region 3 ), and the main peak in the rich branch (region 4). Reac-

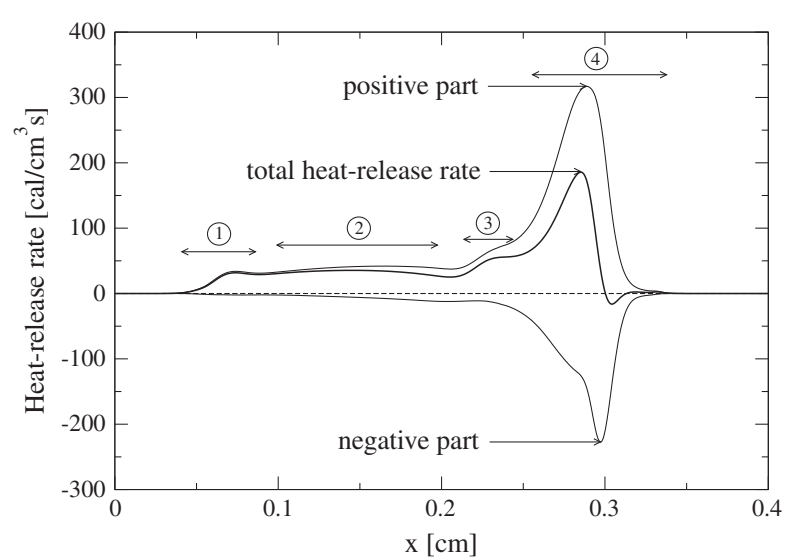

Fig. 8. Heat-release rate along a horizontal slice through the triple flame at $y=0.3 \mathrm{~cm}$. In addition to the total heat-release rate its positive and negative components are shown as well. The numbers show the regions for which the contributions of chemical reactions are analyzed, see text.

tions with a negative heat-release rate are only significant in the fuel rich region.

The heat-release in region 1 is mostly caused by reactions that are also active in the central edge flame region (regions 2 and 3 ) but some reactions show a higher rate or are only active in the lean premixed branch. The dominant ones are:

$$
\begin{aligned}
& \mathrm{HO}_{2}+\mathrm{OH} \rightarrow \mathrm{H}_{2} \mathrm{O}+\mathrm{O}_{2} \quad(17.2 \%) \\
& \mathrm{CH}_{3}+\mathrm{O} \rightarrow \mathrm{CH}_{2} \mathrm{O}+\mathrm{H} \\
& \mathrm{HCO}+\mathrm{O}_{2} \rightarrow \mathrm{CO}+\mathrm{HO}_{2}
\end{aligned}
$$

In region 2, the hydrogen attack of $\mathrm{O}_{2}$ is important (as in region 1). In addition reactions leading to $\mathrm{H}_{2} \mathrm{O}$ and the $\mathrm{CO}_{2}$ cause the heatrelease:

$$
\begin{aligned}
\mathrm{H}+\mathrm{O}_{2}+(\mathrm{M}) & \rightarrow \mathrm{HO}_{2}+(\mathrm{M}) \quad(21.4 \%) \\
\mathrm{H}+\mathrm{OH}+(\mathrm{M}) & \rightarrow \mathrm{H}_{2} \mathrm{O}+(\mathrm{M}) \quad(20.5 \%) \\
\mathrm{CO}+\mathrm{OH} & \rightarrow \mathrm{CO}_{2}+\mathrm{H} \quad(16.2 \%)
\end{aligned}
$$

The small heat-release peak of region 3 overlaps with the large heat release in the rich premixed branch. There are some reactions that show a distinct peak in this region. They are:

$$
\begin{aligned}
\mathrm{CH}_{3}+\mathrm{O} & \rightarrow \mathrm{CH}_{2} \mathrm{O}+\mathrm{H} \quad(10.9 \%) \\
\mathrm{HCCO}+\mathrm{H} & \rightarrow \mathrm{CH}_{2}(\mathrm{~s})+\mathrm{CO} \quad(6.3 \%) \\
\mathrm{C}_{2} \mathrm{H}_{2}+\mathrm{O} & \rightarrow \mathrm{CH}_{2}+\mathrm{CO} \quad(5.9 \%) \\
& \rightarrow \mathrm{HCCO}+\mathrm{H} \quad(4.9 \%)
\end{aligned}
$$

In the fuel rich branch (region 4), we find a variety of reactions responsible for the heat-release. The production reactions of $\mathrm{C}_{3} \mathrm{H}_{6}$ and $\mathrm{C}_{2} \mathrm{H}_{6}$ show the largest heat-release rates. Reactions leading to $\mathrm{H}_{2} \mathrm{O}$ and $\mathrm{CO}$ being the second important ones:

$$
\begin{aligned}
\mathrm{CH}_{3}+\mathrm{CH}_{3}+(\mathrm{M}) & \rightarrow \mathrm{C}_{2} \mathrm{H}_{6}+(\mathrm{M}) \quad(8.6 \%) \\
\mathrm{C}_{2} \mathrm{H}_{3}+\mathrm{CH}_{3} & \rightarrow \mathrm{C}_{3} \mathrm{H}_{6} \quad(5.6 \%) \\
\mathrm{OH}+\mathrm{H}_{2} & \rightarrow \mathrm{H}+\mathrm{H}_{2} \mathrm{O} \quad(5.9 \%) \\
\mathrm{C}_{3} \mathrm{H}_{2}+\mathrm{O}_{2} & \rightarrow \mathrm{HCCO}+\mathrm{CO}+\mathrm{H} \quad(3.9 \%) \\
\mathrm{HCCO}+\mathrm{H} & \rightarrow \mathrm{CH}_{2}(\mathrm{~s})+\mathrm{CO} \quad(4.4 \%)
\end{aligned}
$$

In the region of the rich branch we find reactions with a negative heat-release rate. They are mostly thermal decomposition reactions. The most important one is the decomposition of $\mathrm{C}_{2} \mathrm{H}_{5}$ to $\mathrm{C}_{2} \mathrm{H}_{4}$. Other reactions involve the decomposition of $\mathrm{C}_{3} \mathrm{H}_{7}, \mathrm{C}_{4} \mathrm{H}_{9}, \mathrm{C}_{7} \mathrm{H}_{15}, n-\mathrm{C}_{7} \mathrm{H}_{16}$.

It is interesting to note that the reactions dominating the heatrelease rate in the lean premixed branch and the non-premixed central part of this $n$-heptane edge flame are mostly the same as 
for methane/air edge flames, see e.g. [1]. Only in the rich premixed branch (region 4 ), we find a set of reactions specific to the fuel.

\subsubsection{Fuel-consumption pathways}

Zhang et al. [53] examined the fuel-consumption pathways using several reduced reaction mechanisms for $n$-heptane for a fuel-rich premixed flame $(\phi=1.9)$ and a non-premixed opposedjet diffusion flame. It was found that hydrogen abstraction reactions are the dominant pathway in fuel-rich premixed flames of $n$-heptane. Thermal decomposition reactions become important only at higher local temperatures between $1400-1500 \mathrm{~K}$ where most of the fuel has been consumed already. The principal hydrogen abstractor was found to be the $\mathrm{H}$ radical followed by $\mathrm{OH}$ and $\mathrm{O}$ radicals. The findings for the opposed-jet diffusion flame were similar, involving hydrogen abstraction by $\mathrm{H}$ radicals is the dominant fuel-consumption process. Abstraction by $\mathrm{OH}$ radicals is found to be less important than for the rich premixed flame, but now, thermal decomposition gains importance and competes for the main consumption path.

In Fig. 9 we show the results of a similar reaction-flux analysis in the case of the edge flame. We plot the $10 \%$-isocontours of the reaction rates for $\mathrm{H}$-abstraction reactions of $n-\mathrm{C}_{7} \mathrm{H}_{16}$ separately for the attacking radicals $\mathrm{H}, \mathrm{O}$, and $\mathrm{OH}$. We sum the reaction rates leading to different isomers of the heptyl radical. In addition, the isocontour of the total rate of all thermal decomposition reactions of $n$-heptane is shown as well. We also provide the reaction rates belonging to the isolines to show the difference in importance of the consumption pathways. As in the work of Zhang [53], we find that $\mathrm{H}$ abstraction by the $\mathrm{H}$ radical is the dominating process all along the rich branch and the region around stoichiometric conditions. Only in the lean branch, does $\mathrm{H}$ abstraction by $\mathrm{OH}$ take over the leading role:

rich : $n-\mathrm{C}_{7} \mathrm{H}_{16}+\mathrm{H} \rightarrow \mathrm{C}_{7} \mathrm{H}_{15}+\mathrm{H}_{2}$

lean : $n-\mathrm{C}_{7} \mathrm{H}_{16}+\mathrm{OH} \rightarrow \mathrm{C}_{7} \mathrm{H}_{15}+\mathrm{H}_{2} \mathrm{O}$

Thermal decomposition occurs mostly behind the rich branch where the temperature ranges between $1300-1600 \mathrm{~K}$, but has a lower reaction rate than $\mathrm{H}$ abstraction:

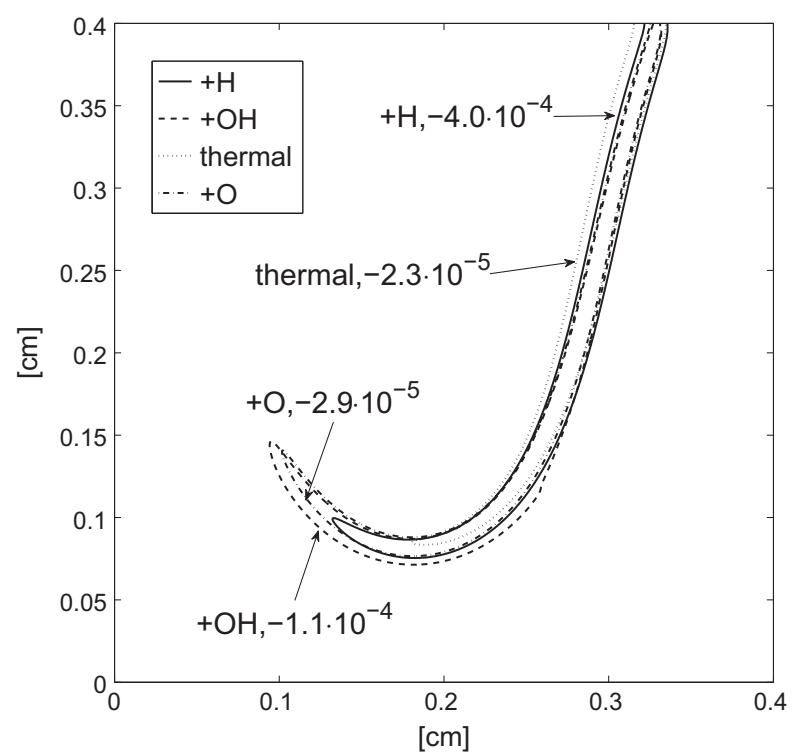

Fig. 9. Main consumption pathways of $n$-heptane. The $10 \%$ isocontours of important reaction rates are shown. The reaction rates $\left(\mathrm{mol} / \mathrm{cm}^{3} \mathrm{~s}\right)$ of the isolines are given. The reaction rates leading to different isomers or belonging to the same reaction class are added.

$$
\begin{aligned}
n-\mathrm{C}_{7} \mathrm{H}_{16} & \rightarrow \mathrm{C}_{5} \mathrm{H}_{11}+\mathrm{C}_{2} \mathrm{H}_{5} \\
& \rightarrow p-\mathrm{C}_{4} \mathrm{H}_{9}+n-\mathrm{C}_{3} \mathrm{H}_{7}
\end{aligned}
$$

The H-abstraction reactions lead to the formation of heptyl isomers. Figure 10 shows the dominant consumption pathways of these heptyl radicals. We find the most important processes to be $\beta$-scission reactions:

$$
\begin{aligned}
\mathrm{C}_{7} \mathrm{H}_{15} & \rightarrow \mathrm{C}_{5} \mathrm{H}_{11}+\mathrm{C}_{2} \mathrm{H}_{4} \\
& \rightarrow p-\mathrm{C}_{4} \mathrm{H}_{9}+\mathrm{C}_{3} \mathrm{H}_{6} \\
& \rightarrow \mathrm{C}_{4} \mathrm{H}_{8}+n-\mathrm{C}_{3} \mathrm{H}_{7} \\
& \rightarrow \mathrm{C}_{2} \mathrm{H}_{5}+\mathrm{C}_{5} \mathrm{H}_{10}
\end{aligned}
$$

The thermal elimination of a hydrogen atom is another important reaction pathway all along the premixed flame branches. Addition-

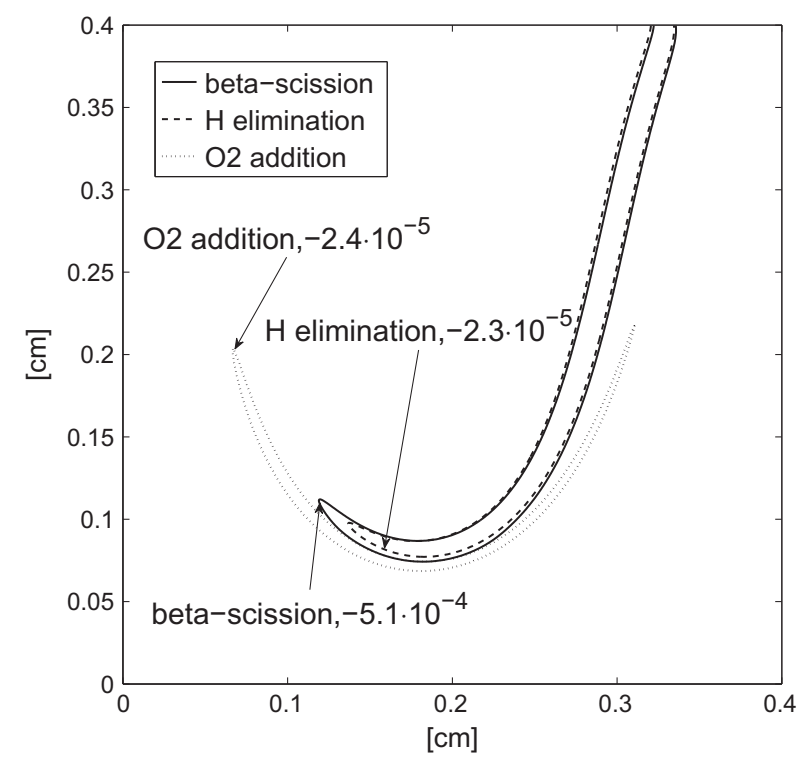

Fig. 10. Important consumption pathways of heptyl radicals shown as $10 \%$ isocontours of reaction rates. The reaction rates of all isomers and channels inside a class of reactions are added. The reaction rates $\left(\mathrm{mol} / \mathrm{cm}^{3} \mathrm{~s}\right)$ of the isolines are given.

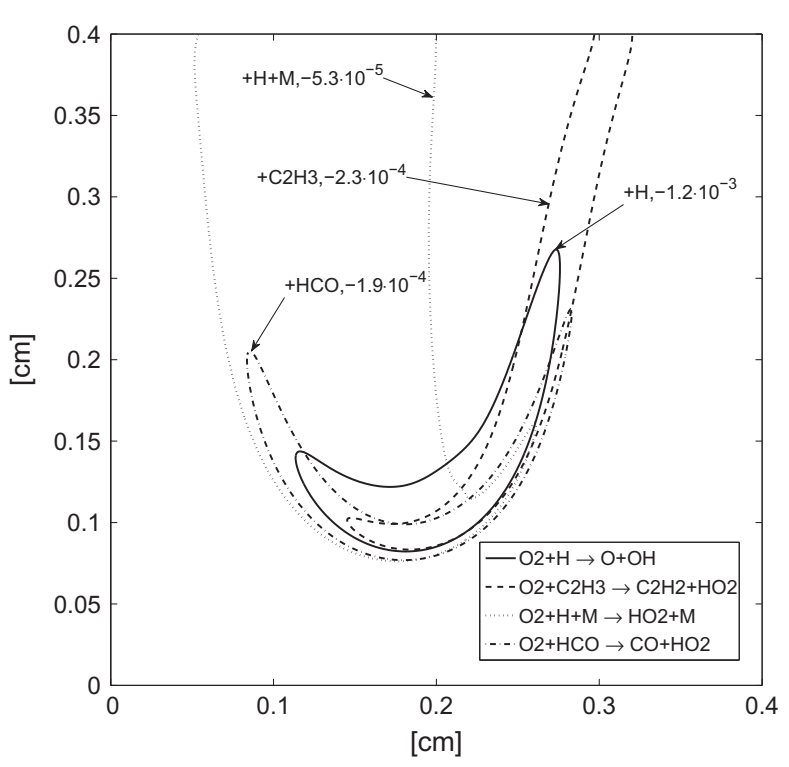

Fig. 11. Main consumption pathways of $\mathrm{O}_{2}$. The $10 \%$ isocontours of important reaction rates are shown. The reaction rates $\left(\mathrm{mol} / \mathrm{cm}^{3} \mathrm{~s}\right)$ of the isolines are given. 


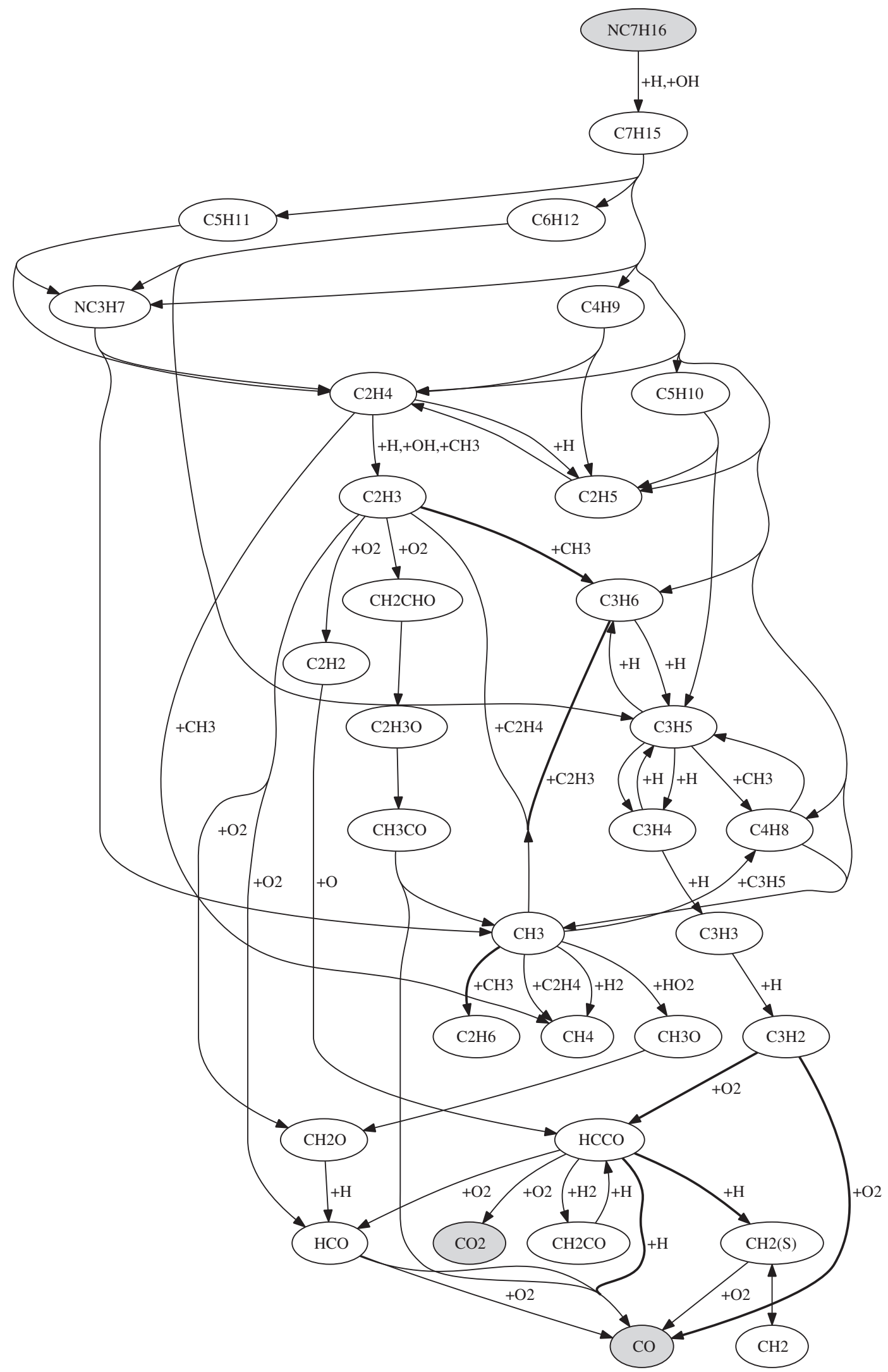

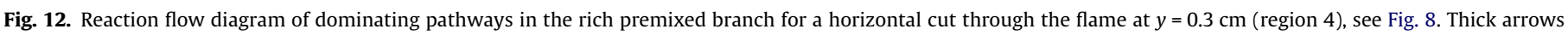
show reactions with a large heat-release rate. Labels next to arrows show reaction partners.

ally, in the preheat zones of the branches we find significant oxygen addition reactions typical of the low-temperature chemistry of heptane:
$\mathrm{C}_{7} \mathrm{H}_{15}+\mathrm{O}_{2} \leftrightarrow \mathrm{C}_{7} \mathrm{H}_{15} \mathrm{O}_{2}$

The reaction rates leading to this pathway are small compared to the rates for $\beta$-scission so that the reactions of the classical low- 
temperature ignition chemistry are only of minor importance, e.g. [26,27].

\subsubsection{Oxygen-consumption pathways}

Figure 11 shows the main consumption pathways for $\mathrm{O}_{2}$. The highest consumption rates are found in the vicinity of the premixed branches. It is the attack by the $\mathrm{H}$ radical that dominates this process:

$\mathrm{O}_{2}+\mathrm{H} \rightarrow \mathrm{O}+\mathrm{OH}$

Other pathways active along the premixed regions are reactions with $\mathrm{C}_{2} \mathrm{H}_{3}$ (rich branch) and $\mathrm{HCO}$ (rich and lean branches):

$$
\begin{gathered}
\mathrm{O}_{2}+\mathrm{C}_{2} \mathrm{H}_{3} \rightarrow \mathrm{C}_{2} \mathrm{H}_{2}+\mathrm{HO}_{2} \\
\mathrm{O}_{2}+\mathrm{HCO} \rightarrow \mathrm{CO}+\mathrm{HO}_{2}
\end{gathered}
$$

The main consumption channel in the diffusion flame is the threebody reaction with $\mathrm{H}$ to $\mathrm{HO}_{2}$. In the same region, there is a production pathway back to $\mathrm{O}_{2}$ due to the attack of $\mathrm{HO}_{2}$ by $\mathrm{OH}, \mathrm{O}$, and $\mathrm{H}$ radicals (not shown).

\subsubsection{Reaction network}

In the following, we use a heuristic algorithm based on Computational Singular Perturbation analysis (CSP) to determine the main reaction network important for the fuel consumption in the edge flame. We do this by producing skeletal mechanisms in the same way as has been done for ignition calculations $[28,29]$ but this time analyzing the chemical states in the edge flame.
We present the results of such an analysis for the horizontal slice through the flame at $y=0.3 \mathrm{~cm}$ for all the regions separately. This way it is possible to discuss the different pathways taken in the rich and lean premixed branches compared with the non-premixed flame in-between. As target species we use $n$-heptane in the premixed regions 1 and $4, \mathrm{CO}$ and $\mathrm{CO}_{2}$ in region 3, and $\mathrm{CO}_{2}$ in the central non-premixed region. The cut-off parameter $\alpha$ on the importance indices is chosen large enough to only show the main reactions connecting the fuel to the main products in each of the regions. Some species appear as local products in the reaction graphs.

There has been no such study for an $n$-heptane edge flame in the literature. Therefore, we compare qualitatively to the work of Xue [20] who did a reaction-flow analysis for a 1D partially-premixed counterflow flame. In their work, a fuel stream of equivalence ratio $\phi=2.0$, and air as oxidizer stream, at near ambient conditions were used.

Figures 12 and 13 show the results for the two regions 4 and 3 . In the rich branch we find mainly three pathways which start from the products of the $\beta$-scission reactions of the heptyl radicals, which were mainly produced by $\mathrm{H}$ abstraction from the fuel molecule. The first pathway involves methyl radicals $\mathrm{CH}_{3}$ and proceeds via $\mathrm{CH}_{2} \mathrm{O}$ and $\mathrm{HCO}$. The second pathway follows a sequence of hydrocarbons with successively removed $\mathrm{H}$ atoms starting with $\mathrm{C}_{3} \mathrm{H}_{6}$ with a central role played by $\mathrm{C}_{3} \mathrm{H}_{5}$ because several pathways originating from the $\beta$-scission products of heptyl radicals, i.e. $\mathrm{C}_{6} \mathrm{H}_{12}, \mathrm{C}_{5} \mathrm{H}_{10}, \mathrm{C}_{4} \mathrm{H}_{8}$ and $\mathrm{C}_{3} \mathrm{H}_{6}$, proceed via this species. The third pathway is a similar sequence of hydrocarbons involving $\mathrm{C}_{2} \mathrm{H}_{x}$ and proceeding via $\mathrm{C}_{2} \mathrm{H}_{2}$ and $\mathrm{HCCO}$ to $\mathrm{CO}$ and $\mathrm{CO}_{2}$. In their par-

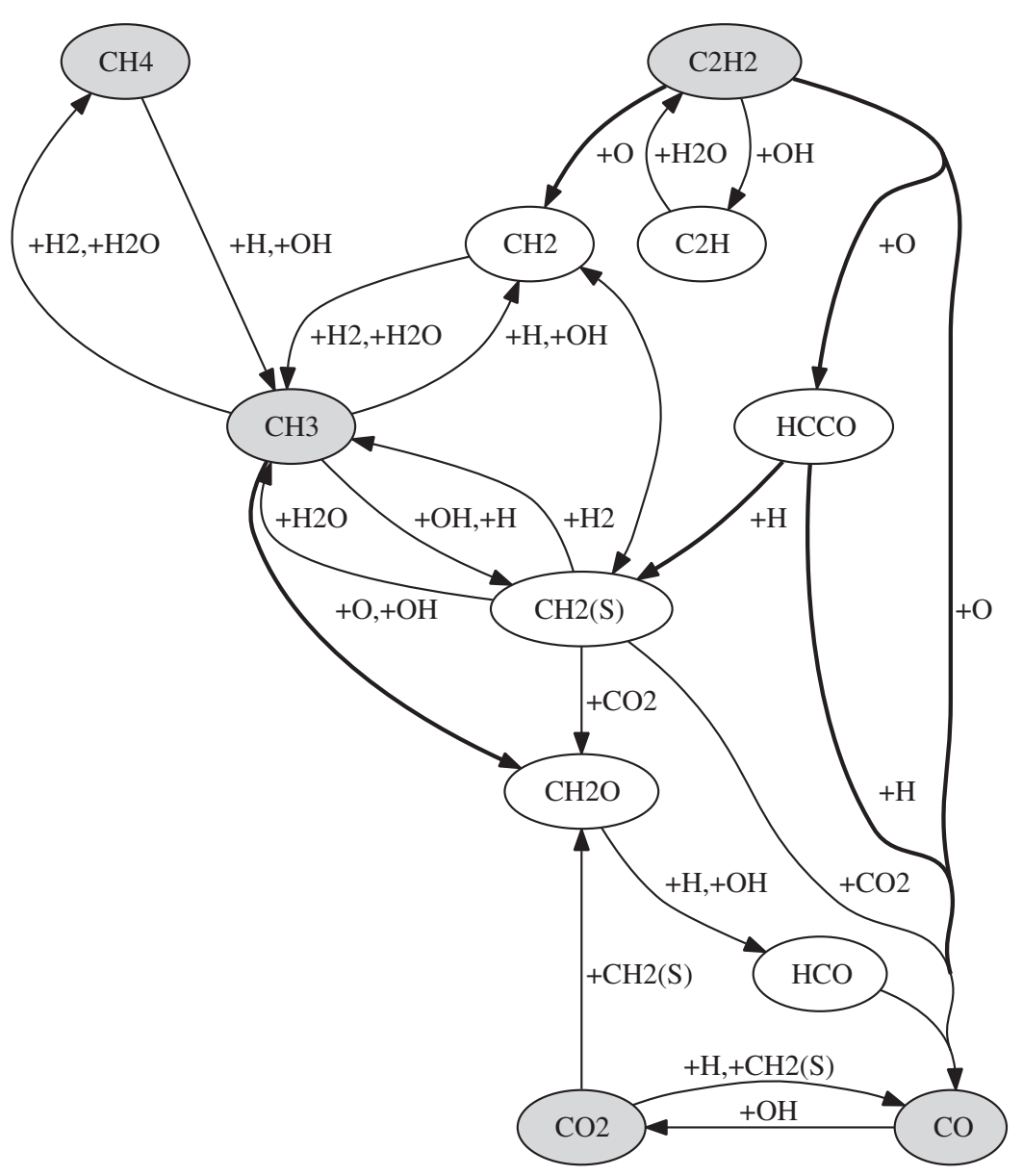

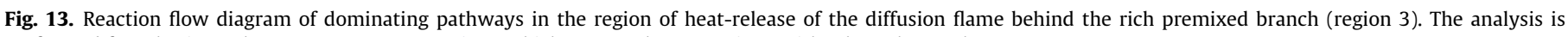
performed for a horizontal cut at $y=0.3 \mathrm{~cm}$, see Fig. 8. Thick arrows show reactions with a large heat-release rate. 
tially-premixed counterflow flame, Xue identified overall the same three main pathways but there are some differences especially for the pathway involving $\mathrm{C}_{3} \mathrm{H}_{x}$. They show the central role of $\mathrm{C}_{3} \mathrm{H}_{5}$ but their pathway to $\mathrm{CO}$ proceeds via $\mathrm{C}_{2} \mathrm{H}_{3} \mathrm{HCO}$ and via $\mathrm{C}_{4} \mathrm{H}_{6}$ which is produced from $\mathrm{C}_{3} \mathrm{H}_{3}$. We do not find these two species for the chosen tolerance in our reaction network, the path to $\mathrm{CO}$ proceeds via $\mathrm{C}_{3} \mathrm{H}_{2}$. The reason for this discrepancy can be the different reaction mechanisms used (Held et al. [54] with 41 species and 275 reactions) or the differences between the two flow configurations.

In case of the rich side of the non-premixed flame (region 3 ) the resulting reaction network does not connect $\mathrm{CO}_{2}$ to heptane unless a very small threshold for the importance indices is chosen. Instead, the reaction flow originates from $\mathrm{C}_{2} \mathrm{H}_{2}$ and $\mathrm{CH}_{3} / \mathrm{CH}_{4}$ and does not involve hydrocarbons with more than two carbon atoms because, in region 3, heptane and the higher hydrocarbons are already completely consumed. The graph starts with $\mathrm{C}_{2} \mathrm{H}_{2}$ and $\mathrm{CH}_{3}$ / $\mathrm{CH}_{4}$ because there are no important production reactions for these species in this region, rather they enter this region of the flame by transport processes.

To further strengthen this argument, Fig. 14 shows the mole fractions of species that participate in the main fuel-consumption pathways and occur in significant amount. We see that only $\mathrm{C}_{2} \mathrm{H}_{2}$ and $\mathrm{CH}_{3}$ persist into the diffusion flame. The species above them in the sequence of fuel consumption (network graph of region 4) are already consumed in the rich premixed branch. Similar conclusions were found in the 1D partially-premixed counterflow flame of Xue et al. [20].

The analysis of region 2, i.e. the non-premixed flame, results only in a few reactions of the hydrogen chemistry and the conversion of $\mathrm{CO}$ into $\mathrm{CO}_{2}$ which are important for the target species $\mathrm{CO}_{2}$, see Fig. 15. Molecular hydrogen, $\mathrm{CO}$, and $\mathrm{O}$ radicals which originate in the premixed branches can be considered the initial species that burn in this region of the diffusion flame. This finding agrees with previous works on triple flames of other hydrocarbons, e.g. [6,8].

Finally, Fig. 16 shows the main reaction network of the lean premixed branch in region 1 . Initially, $n$-heptane reacts with $\mathrm{OH}$ to produce heptyl radicals. The high abundance of $\mathrm{O}_{2}, \mathrm{O}$, and $\mathrm{OH}$ favors reaction paths involving these species. $\mathrm{O}_{2}$-attachment/detachment reactions are important for many species but have been removed from the reaction network for clarity since they do not participate in the reaction flow to $\mathrm{CO}$ and $\mathrm{CO}_{2}$. The pathways to $\mathrm{CO}$ are more complex in the lean branch compared to the other regions. Many pathways proceed via $\mathrm{C}_{2} \mathrm{H}_{4}, \mathrm{C}_{2} \mathrm{H}_{3}$, and $\mathrm{CH}_{3}$, showing the central role of these species.

Overall, the analysis confirms the qualitative understanding of an edge/triple flame in that hydrocarbons which remain behind

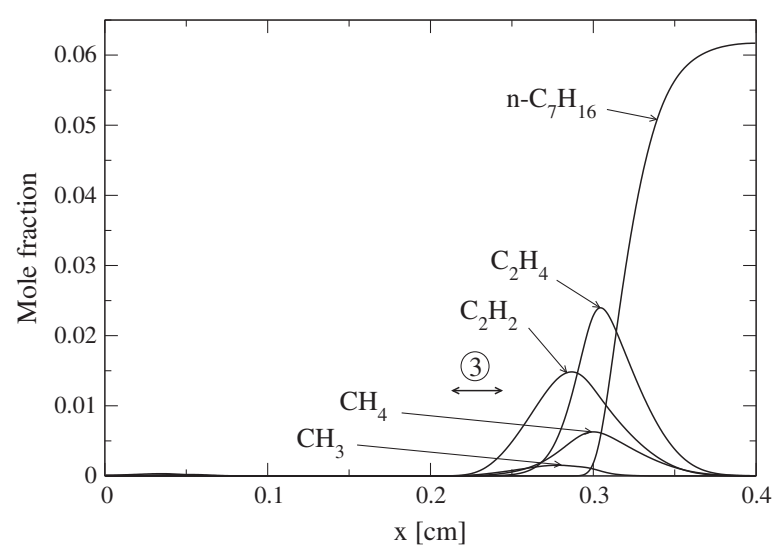

Fig. 14. Mole fractions of species participating in the major fuel-consumption pathway along a horizontal slice through the flame at $y=0.3 \mathrm{~cm}$. The location of the heat-release peak on the rich side of the diffusion flame is marked (region 3), see Fig. 8. the fuel-rich premixed branch react in a non-premixed flame with oxygen-containing species left over from the lean-premixed combustion in the lean branch. Similar to our previous study on a $\mathrm{CH}_{4}$ /air triple flame [19], we also find a two-layered structure of the trailing diffusion flame for the $n$-heptane/air triple flame. On the fuel-lean side, it is $\mathrm{H}_{2}$ and $\mathrm{CO}$ that feed the diffusion flame. On the fuel-rich side, instead, it is $\mathrm{C}_{2} \mathrm{H}_{2}$ and remaining $\mathrm{CH}_{3} / \mathrm{CH}_{4}$ which are burning in the diffusion flame behind the rich premixed branch.

\subsubsection{Explosive modes}

CSP offers the opportunity to study chemical processes which show a divergent behavior and move the system away from equilibrium. These divergent processes lead to modes with eigenvalues having a positive real part. These so-called explosive modes have been used recently to analyze the complex two-stage ignition behavior of $n$-heptane [49]. It was found that a pair of explosive modes exists during the first stage of the ignition event and a single explosive mode is found during the second stage. The reaction makeup of the modes during the first stage confirmed the accepted low-temperature branching sequence of $n$-heptane as controlling the ignition. The second stage was found to be controlled by chain-thermal runaway involving branching due to the decomposition of $\mathrm{H}_{2} \mathrm{O}_{2}$.

Recently, the analysis of explosive modes was used to identify the location of premixed flame fronts and study the significance of auto-ignition in a lifted hydrogen/air jet-flame by Lu et al. [50,55]. It was shown that an explosive mode exists only in the preheat zone of a premixed flame. This mode was shown to involve mostly the temperature evolution and partly $\mathrm{H}$ radicals. It was concluded that build-up of a radical pool is of minor importance for the explosive behavior in a premixed flame compared to homogeneous ignition.

In our recent work, we studied the explosive modes in a $\mathrm{CH}_{4} / \mathrm{air}$ triple flame [19]. We identified two regions of explosive behavior: one in the preheat zone of the premixed branches and the main one approximately following the isocontours of the $\mathrm{CH}_{4}$ consumption rate. There are two explosive modes in each of these zones. The dominating mode, i.e. the one with fastest time scale, was found to involve the temperature evolution, consistent with the findings of $\mathrm{Lu}[50,55]$. We also highlighted the importance of

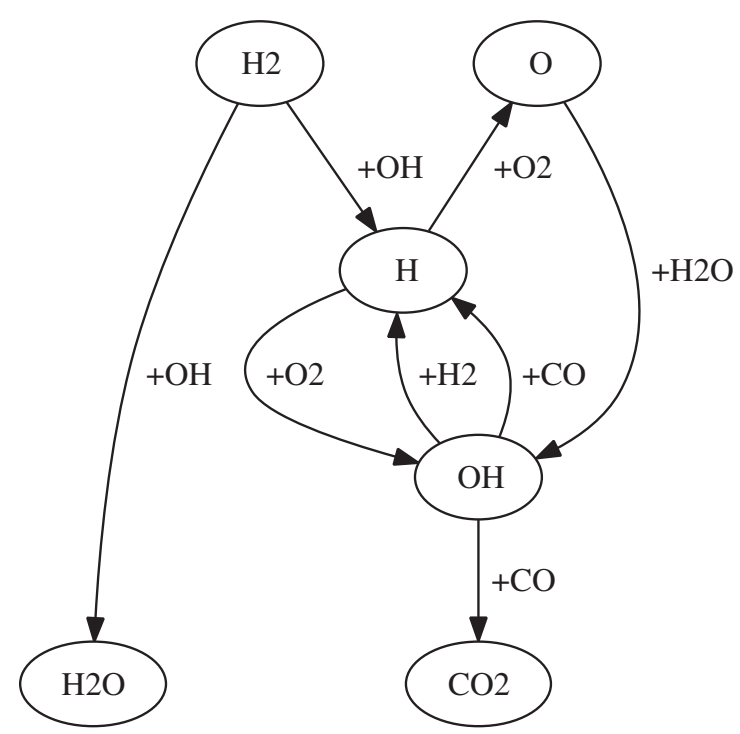

Fig. 15. Reaction flow diagram of dominating pathways in the region of broad heatrelease of the diffusion flame (region 2). The analysis is performed for a horizontal cut at $y=0.3 \mathrm{~cm}$, see Fig. 8 . 
transport processes in initiating the chemical processes of the explosive mode.

In Fig. 17 we present the explosive modes in the present $n$-heptane triple flame similar to the analysis for a $\mathrm{CH}_{4} /$ air triple flame [19]. Up to two explosive modes can be identified. The real part of the eigenvalue of these modes is plotted for three cuts through the flame. Temperature isolines are shown as well for orientation. We find explosive modes in the premixed reaction zones of the triple flame, but most significantly at the flame tip and in the rich branch. In general, there are two regions with explosive behavior, the main one (with faster time scale, i.e. larger eigenvalue) at temperatures between $1200 \mathrm{~K}$ and $1800 \mathrm{~K}$ and a second one at low temperatures between $600 \mathrm{~K}$ and $800 \mathrm{~K}$. These findings are similar to the results we obtained for the $\mathrm{CH}_{4} /$ air triple flame [19]. The slower explosive mode (dashed lines) plays a role at the boundaries of explosive regions. There, the two real explosive modes combine, and exhibit a complex conjugate pair of eigenvalues. The real part of this pair of eigenvalues changes its sign in a narrow spatial region and the explosive behavior ends.

Analyzing the CSP pointer of the fastest explosive mode at its maximum in the main explosive region we find that it points to temperature as the variable most affected by the mode. There are several other species involved as well but to a lesser degree. The most important ones are: $\mathrm{H}, \mathrm{O}_{2}, \mathrm{OH}, \mathrm{O}$ at the flame tip; $\mathrm{O}_{2}, \mathrm{C}_{3} \mathrm{H}_{6}$,

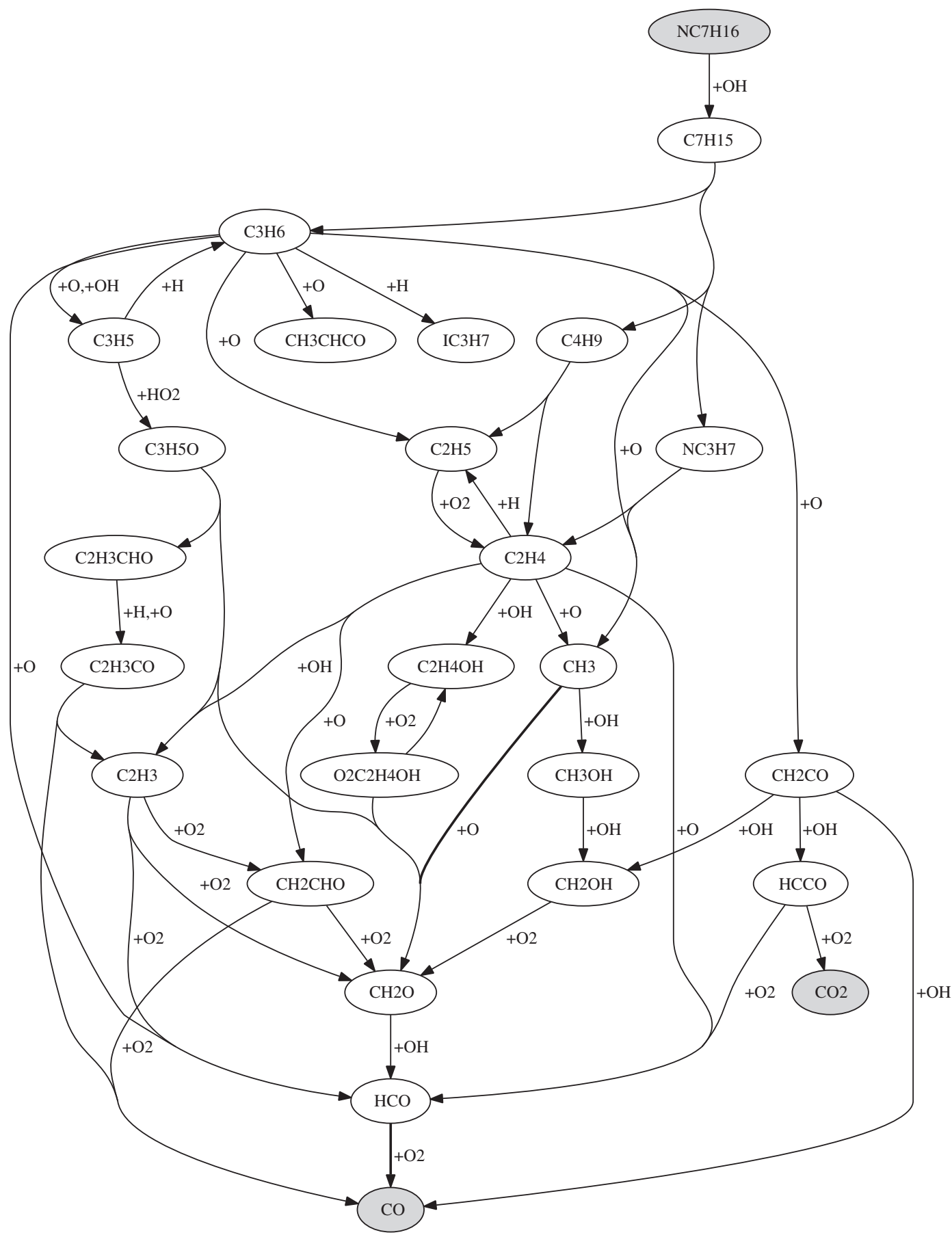

Fig. 16. Reaction flow diagram of dominating pathways in the region of the lean premixed branch (region 1 ). The analysis is performed for a horizontal cut at $y=0.3 \mathrm{~cm}$, see Fig. 8. 


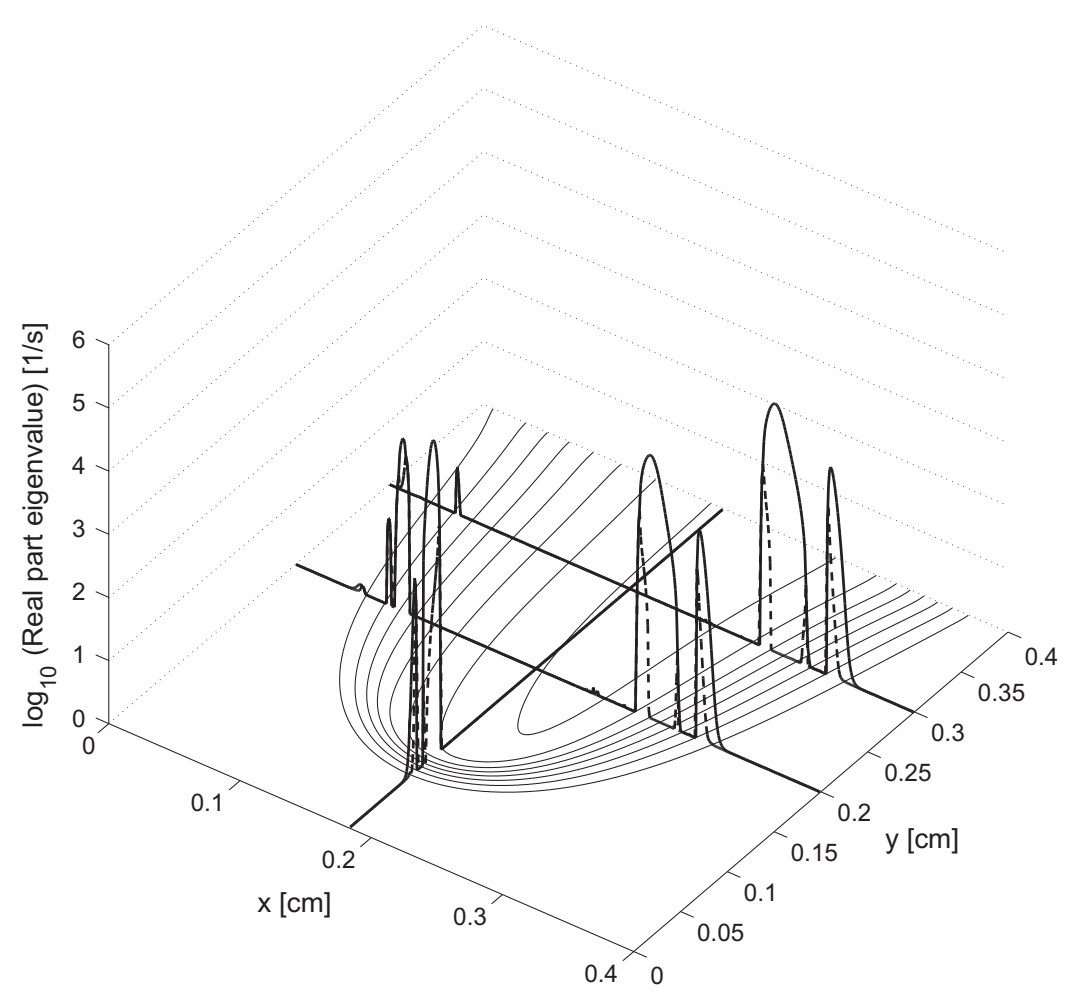

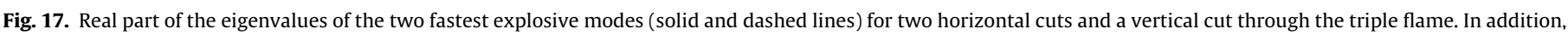
temperature isolines are shown from $600 \mathrm{~K}$ to $2000 \mathrm{~K}$ in $200 \mathrm{~K}$ increments.

$\mathrm{C}_{2} \mathrm{H}_{x}$ in the rich branch; and $\mathrm{CO}_{2}, \mathrm{H}_{2} \mathrm{O}, \mathrm{O}_{2}$, and $\mathrm{H}_{2}$ in the lean branch. The participation indices of the explosive mode, therefore, indicate reactions and transport terms which participate in the divergent time evolution of temperature and these species.

In the lean branch we find mostly reactions of the $\mathrm{CH}_{4} / \mathrm{H}_{2}$ base mechanism showing a significant participation index in the explosive mode. The most important ones with positive index are:

$$
\begin{aligned}
\mathrm{H}+\mathrm{O}_{2} & \rightarrow \mathrm{O}+\mathrm{OH} \\
\mathrm{CO}+\mathrm{OH} & \rightarrow \mathrm{CO}_{2}+\mathrm{H} \\
\mathrm{HO}_{2}+\mathrm{H} & \rightarrow 2 \mathrm{OH} .
\end{aligned}
$$

Reactions with large negative participation index are:

$$
\begin{aligned}
\mathrm{H}+\mathrm{O}_{2}+\mathrm{M} & \rightarrow \mathrm{HO}_{2}+\mathrm{M} \\
\mathrm{HO}_{2}+\mathrm{OH} & \rightarrow \mathrm{H}_{2} \mathrm{O}+\mathrm{O}_{2} \\
\mathrm{O}+\mathrm{OH} & \rightarrow \mathrm{H}+\mathrm{O}_{2} .
\end{aligned}
$$

There is, of course, an ambiguity in choosing the direction (multiplication by -1) of the eigenvector of any mode, and in particular for the explosive mode of interest. Moreover, the choice determines the sign of the associated participation indices. In the present explosive mode analysis, we employ the convention of choosing the direction of the eigenvector in the direction of increasing temperature. We find that this convention leads to explosive mode participation index signs for the above reactions that are in agreement with the signs of sensitivity coefficients for these reactions in previous flame studies [56,57]. In fact, the above reactions exhibit the largest sensitivity coefficients, with the corresponding signs, with respect to flame velocity in atmospheric lean premixed methane-air flames $[56,57]$. Reactions with positive sensitivity coefficients, that increase the reactivity of the system leading to higher flame velocities, exhibit positive participation indices in the explosive mode. Conversely, reactions with negative sensitivity coefficents exhibit negative participation indices.
Thus, the analysis of the explosive mode leads here to the same conclusions as the sensitivity analysis of flame velocity. The central role of the highly temperature-dependent chain-branching reaction $\mathrm{H}+\mathrm{O}_{2} \rightarrow \mathrm{O}+\mathrm{OH}$ and the conversion of $\mathrm{HO}_{2}$ to two very reactive $\mathrm{OH}$ radicals is confirmed as increasing the reactivity of the chemical system. The conversion of $\mathrm{CO}$ to $\mathrm{CO}_{2}$ produces heat without losing an active radical. The reactions found with negative participation index are leading to the less reactive $\mathrm{HO}_{2}$ or reduce the amount of radicals in the system, thereby inhibiting the explosive behavior.

The analysis of the fast explosive mode at the flame tip leads to similar results. The same reactions are found to promote or inhibit the explosive behavior. Only the three-body reaction leading to $\mathrm{HO}_{2}$ lost its importance. In addition, several chain-propagation reactions (some of which lead to heat-release) become important in increasing the reactivity of the system. They are:

$$
\begin{aligned}
\mathrm{HCO}+\mathrm{M} & \rightarrow \mathrm{H}+\mathrm{CO}+\mathrm{M} \\
\mathrm{OH}+\mathrm{H}_{2} & \rightarrow \mathrm{H}+\mathrm{H}_{2} \mathrm{O} \\
\mathrm{CH}_{2}(\mathrm{~s})+\mathrm{O}_{2} & \rightarrow \mathrm{CO}+\mathrm{OH}+\mathrm{H} \\
\mathrm{CH}_{3}+\mathrm{OH} & \rightarrow \mathrm{CH}_{2}(\mathrm{~s})+\mathrm{H}_{2} \mathrm{O} .
\end{aligned}
$$

These findings agree qualitatively with the sensitivity coefficients for flame velocity in a premixed stoichiometric atmospheric methane-air flame [56,57].

In the rich branch, it is again the reaction $\mathrm{H}+\mathrm{O}_{2} \rightarrow \mathrm{O}+\mathrm{OH}$ which shows the largest positive participation index. The same reactions found at the flame tip have a positive participation index in the rich branch as well. But additionally, we find reactions specific to the combustion of larger hydrocarbons that lead to an increased reactivity of the system. In general, these reactions convert less-reactive species into the very reactive radicals $\mathrm{H}, \mathrm{O}$, and $\mathrm{OH}$ which participate in the chain-branching process of the $\mathrm{H}_{2} / \mathrm{O}_{2}$ system. The most important ones are: 


$$
\begin{aligned}
\mathrm{C}_{3} \mathrm{H}_{5}-\mathrm{a} & \rightarrow \mathrm{C}_{3} \mathrm{H}_{4}-\mathrm{a}+\mathrm{H} \\
\mathrm{C}_{2} \mathrm{H}_{3}+\mathrm{O}_{2} & \rightarrow \mathrm{CH}_{2} \mathrm{CHO}+\mathrm{O} \\
\mathrm{CH}_{3}+\mathrm{H}_{2} & \rightarrow \mathrm{CH}_{4}+\mathrm{H} .
\end{aligned}
$$

In the second explosive region, i.e. in the preheat zones of the premixed branches, the CSP pointer does not point to temperature as the most important affected variable even though it is still important. This region of explosive behavior is most significant in front of the rich branch of the triple flame in the temperature range between $600 \mathrm{~K}$ and $800 \mathrm{~K}$. There, the CSP pointer of the explosive mode points to species of the low-temperature chemistry of $n$-heptane. These species are $\mathrm{C}_{7} \mathrm{H}_{15} \mathrm{O}_{2}-x$ and $n-\mathrm{C}_{7}$ ket $x y$ with $x=\{2,3\}$ and $y=\{4,5\}$. The following reactions show the largest associated positive participation indices:

$$
\begin{aligned}
\mathrm{C}_{7} \mathrm{H}_{15} \mathrm{O}_{2}-x & \rightarrow \mathrm{C}_{7} \mathrm{H}_{14} \mathrm{OOH} x-y \\
\mathrm{C}_{7} \mathrm{H}_{14} \mathrm{OOH} x-y+\mathrm{O}_{2} & \rightarrow \mathrm{C}_{7} \mathrm{H}_{14} \mathrm{OOH} x-y \mathrm{O}_{2} \\
\mathrm{C}_{7} \mathrm{H}_{14} \mathrm{OOH} x-y \mathrm{O}_{2} & \rightarrow n-\mathrm{C}_{7} \text { ket } x y+\mathrm{OH} \\
\mathrm{CH}_{3}+\mathrm{HO}_{2} & \rightarrow \mathrm{CH}_{3} \mathrm{O}+\mathrm{OH} \\
\mathrm{C}_{2} \mathrm{H}_{5}+\mathrm{HO}_{2} & \rightarrow \mathrm{C}_{2} \mathrm{H}_{5} \mathrm{O}+\mathrm{OH} .
\end{aligned}
$$

Most of these reactions participate in the low-temperature chainbranching mechanism through ketohydroperoxide species leading to $\mathrm{OH}$ radicals which accelerate the rate of fuel oxidation [27]. Other reactions with positive index convert the $\mathrm{HO}_{2}$ radical to OH. Reactions with negative participation index are found to lead away from these pathways. The most important ones are:

$$
\begin{aligned}
\mathrm{CH}_{3}+\mathrm{O}_{2}+\mathrm{M} & \rightarrow \mathrm{CH}_{3} \mathrm{O}_{2}+\mathrm{M} \\
\mathrm{CH}_{3} \mathrm{O}+\mathrm{O}_{2} & \rightarrow \mathrm{CH}_{2} \mathrm{O}+\mathrm{HO}_{2} \\
\mathrm{C}_{2} \mathrm{H}_{3}+\mathrm{O}_{2} & \rightarrow \mathrm{CH}_{2} \mathrm{O}+\mathrm{HCO} \\
\mathrm{C}_{7} \mathrm{H}_{14} \mathrm{OOH} x-y \mathrm{O}_{2} & \rightarrow \mathrm{C}_{7} \mathrm{H}_{14} \mathrm{OOH} x+\mathrm{O}_{2} \\
\mathrm{HO}_{2}+\mathrm{HO}_{2} & \rightarrow \mathrm{H}_{2} \mathrm{O}_{2}+\mathrm{O}_{2} .
\end{aligned}
$$

Overall, these findings suggest that there are two different mechanisms responsible for the explosive behavior in the main region inside the premixed branches and in the low-temperature preheat region. In the premixed branches, thermal runaway of the chainbranching $\mathrm{H}_{2} / \mathrm{O}_{2}$ system seems to be the explosive process while in the preheat region it is the build-up of certain species of the low-temperature ignition chemistry specific to $n$-heptane.

Even though we find an explosive mode related to the low-temperature ignition chemistry of heptane, the major flame properties of the edge flame are not strongly influenced by it because of the generally low reaction rates and heat-release rates found in this low-temperature region ahead of the premixed branches.

By choosing the direction of the explosive eigenvector in the direction of increasing temperature we found that reactions with positive participation index increase the reactivity of the chemical system, thereby promoting the explosive behavior, while reactions with negative participation index decrease the reactivity, inhibiting explosive behavior. A more detailed analysis of explosive modes will be the topic of future research.

The CSP analysis of explosive modes has shown a strong similarity to the traditional sensitivity analysis. It has to be pointed out that a sensitivity analysis of this 2D system would be an enormous task. CSP offers the opportunity to obtain similar information as a post-processing tool in different regions of the flame which is clearly an advantage.

\subsection{Similarity to one-dimensional flames}

For a qualitative understanding of an edge flame it is interesting to look for similarities to classical one-dimensional flame structures. The simple picture of a triple flame is that it can be thought of as an ensemble of premixed flames each burning into a different mixture composition thereby leading to the curved lean and rich branches of a triple flame. Because of the incomplete combustion in the lean and rich branches, further combustion can take place in a diffusion flame in-between the branches. However, there is a strong interaction between the different flame regions. These interactions would be stronger the smaller the thickness of the mixing layer. The diffusion flame is anchored by the flame edge. But also the premixed branches are strongly influenced by the high temperature and radicals that are available in-between the branches. This can be easily seen by comparing cuts perpendicular to the flame surface to simple premixed flames. On the rich branch, for example, the edge flame burns into a mixture of equivalence ratio $\phi \approx 3.5$ at $400 \mathrm{~K}$. Such a freely propagating premixed flame is close to the rich flammability limit for heptane in air at $25^{\circ} \mathrm{C}$ [58]. In previous work, we computed a premixed flame of $n$-heptane at $\phi=2.5$ and $400 \mathrm{~K}$ unburned gas temperature [51]. This flame, for example, burns with approximately $5.4 \mathrm{~cm} / \mathrm{s}$ and has a thermal thickness of $0.28 \mathrm{~cm}$. The rich premixed branch of the edge flame burns with significantly larger speed and has a thermal thickness between $0.05 \mathrm{~cm}$ and $0.08 \mathrm{~cm}$. These quantities can only be estimated in the two-dimensional configuration of an edge flame. The exact values depend on how the flame front is defined and they vary along the premixed branch.

The importance of interactions between the diffusion flame and the premixed branches for their propagation speed and flamability limits are well known for methane/air triple flames, e.g. [2].

Analyzing the propagation speed of the leading edge on the computational grid we find that it burns along the stoichiometric mixture fraction line but with a lower speed compared to a stoichiometric premixed flame. This can also be seen from the lower heatrelease rate in Fig. 7. This is an effect of the flame curvature and is consistent with the observed minimum of the velocity in front of the edge of $60 \mathrm{~cm} / \mathrm{sec}$ caused by the flow-divergence effect [5].

In Fig. 18 we show profiles of the heat-release rate for an opposed-jet configuration of partially-premixed fuel and oxidizer streams. Similar calculations have been performed for heptane by Xue et al., e.g. [20]. The OPPDIF tool of CHEMKIN [59] is used to obtain these profiles. The distance between the nozzles is set to $0.4 \mathrm{~cm}$, i.e. the same as the size of our computational domain for the edge flame. The inflow velocities for both streams are set to $50 \mathrm{~cm} / \mathrm{s}$. This value is chosen because it approximately centers the flame between the nozzles and the width of the flame structure is similar to the width of the edge flame. Decreasing the inflow velocities leads to wider profiles and the magnitude of the heatrelease rate decreases but the qualitative features remain. The

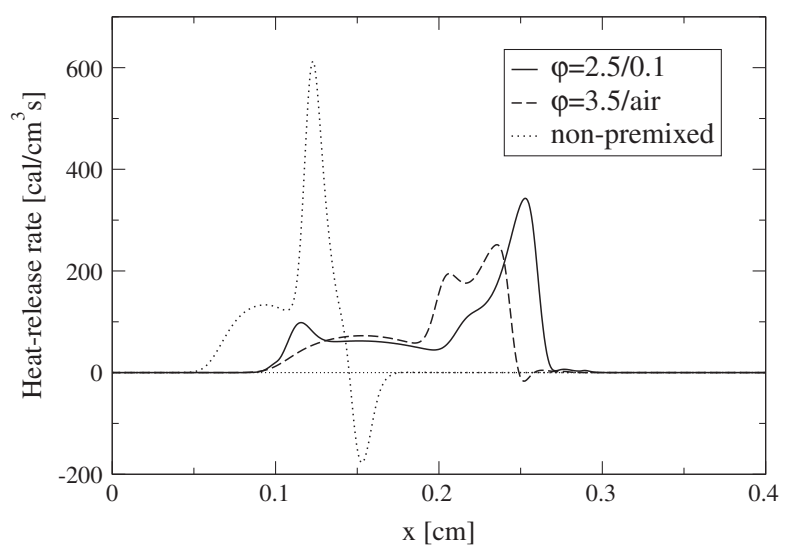

Fig. 18. Profiles of the heat-release rate for a one-dimensional opposed-jet configuration using premixed fuel and oxidizer streams. The equivalence ratios 2.5/3.5/non-premixed are used for the fuel stream (right-hand side). Pure air and an equivalence ratio of 0.1 are used for the oxidizer stream, see plot legend. The inlet temperature is $400 \mathrm{~K}$ at atmospheric pressure. 
temperature of both inflows is $400 \mathrm{~K}$ and atmospheric pressure conditions are used. Several calculations are shown using different equivalence ratios in the fuel and oxidizer streams.

The first one is for a non-premixed fuel stream (entering on the right side of the domain) and pure air as oxidizer. We find a single peak of heat-release on the fuel side and a broad lower peak on the oxidizer side. In the second calculation a premixed fuel stream is used at an equivalence ratio of 3.5. This introduces a second peak located on the fuel-stream side of the first one while the wide lower peak on the oxidizer side persists. This second peak is caused by the rich premixed flame close to the fuel nozzle and grows relative to the first one, the more oxidizer the fuel stream contains. The last calculation uses an equivalence ratio of 2.5 on the fuel-rich side and 0.1 for the oxidizer stream. This leads to two distinct peaks of heat-release of the lean and rich premixed flames and a plateau in-between. The main peak found for the non-premixed case almost vanishes and is overlapped with the main peak of the rich premixed flame on the fuel-stream side. The qualitative features are the same as seen for the horizontal cut through the edge flame at $y=0.3 \mathrm{~cm}$, i.e. in the region behind the flame tip, see Fig. 8, even though in the edge flame we have pure air on the oxidizer side and an equivalence ratio of 3.5 on the fuel side. The variation of heatrelease rate with equivalence ratio obtained with OPPDIF is qualitatively similar to earlier works on methane/air triple flames, e.g. [2] and heptane flames [20]. These 1D calculations were used successfully to study the influence of the equivalence ratio of the fuel stream and strain rates on the structure and chemistry of partiallypremixed flames. Xue et al. [20] studied especially the main chemical pathways and the interactions of diffusion flame and the rich premixed branch. Qualitatively the findings agree with the results of our edge flame, even though there are quantitative differences caused by the more complex structure of this 2D flame.

\subsection{Dependence on skeletal mechanism}

In our previous work, we compared the accuracy of a set of skeletal mechanisms of $n$-heptane/air combustion in calculations of laminar premixed flames [51]. These skeletal mechanisms were developed using CSP based on homogeneous ignition calculations $[28,29]$ and showed very good accuracy for the calculation of main premixed flame properties, e.g. flame speeds, main species profiles. We found deviations when very lean or very rich premixed flames were studied which were caused by differences in the extent to which the low-temperature ignition chemistry was represented in the skeletal mechanisms. Only one of the mechanisms is considered here. It consists of 66 species and 326 reversible reactions (M66). It was developed from a database of homogeneous ignition calculations at constant volume using equivalence ratios $\phi$ $=\{0.5,1.0,2.0\}$, initial temperatures $T=\{1000 \mathrm{~K}, 1250 \mathrm{~K}\}$ and $1 \mathrm{~atm}$ initial pressure. By using these initial temperatures, lowtemperature ignition chemistry was implicitly neglected. This way, a relatively small skeletal mechanism results that yields good results if low-temperature chemistry is of minor interest. We found the most significant deviations from the detailed mechanism in a premixed flame of equivalence ratio $\phi=2.5$. There, low-temperature chemistry leads to a secondary peak of heat-release in the preheat zone at temperatures around $700 \mathrm{~K}$. This secondary heat-release alters the temperature profile and leads to higher concentrations of radicals involved in the low-temperature chemistry like $\mathrm{OH}, \mathrm{HO}_{2}$, and $\mathrm{H}_{2} \mathrm{O}_{2}$ [51].

It is interesting to see if there are such effects in the 2D triple flame studied here since the premixed branches burn a mixture spanning a wide range of lean and rich equivalence ratios. The heat-release rates obtained with both mechanisms are shown for several horizontal cuts through the triple flame in Fig. 19. The first cut is done through the location of maximum heat-release rate.
The following cuts are done at increments of $0.78 \mathrm{~mm}$ downstream from this location. We find overall, a very good agreement between the two mechanisms. The maximum heat-release rate is only $2 \%$ lower for M66. On the rich side, we find a small spatial shift in the profiles which grows in the downstream direction. The edge flame calculated with M66 is slightly narrower on the rich side. The reason for this difference is not clear at this point. It might be caused by the small difference in heat-release which would influence the expansion and divergence of the flow field.

Overall we do not see a significant effect of the removed lowtemperature chemistry of M66 in the heat-release profiles compared to the findings in rich premixed flames [51]. The heat-release rate is much larger along the branches of the edge flame hiding the small effect of low-temperature chemistry.

In Table 3 we compare the maximum mole fractions of species participating in the main reaction flows - i.e. Figs. 12, 16, and 15 that result from using the skeletal mechanism M66 with the results of the complete reaction mechanism M560. The largest errors occur for species that exist as several isomers and for larger hydrocarbons in general. Most of the species show larger mole fractions because the species in Table 3 participate in the major reaction flows and competing reaction channels were removed to obtain the skeletal mechanism. Once the chemical system reaches species of the $\mathrm{CH}_{4}$ base mechanism, the differences between the two

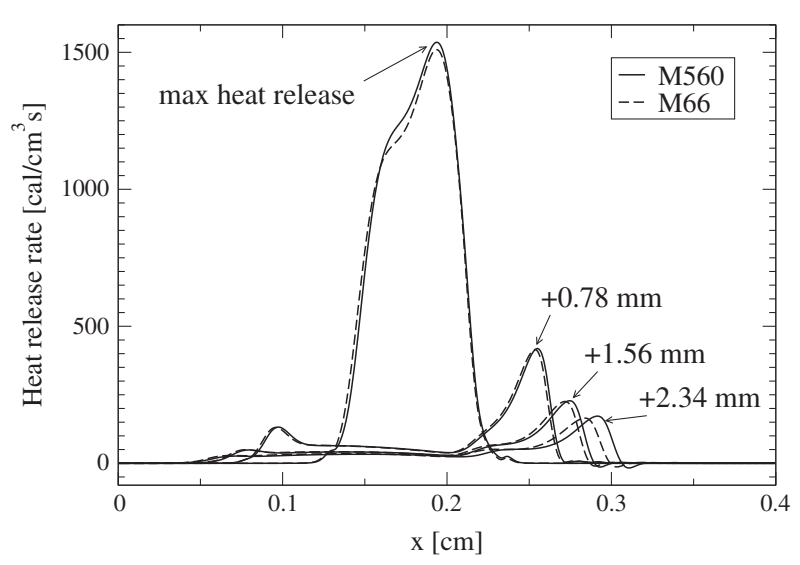

Fig. 19. Heat-release rate profiles for horizontal cuts through the triple flame for the two mechanism M560 and M66. The first cut is at the location of maximum heat-release rate. The following cuts are done for an additional $0.78 \mathrm{~mm}$ downstream.

\section{Table 3}

Difference in the predicted maximum mole fractions of species belonging to the main reaction flows of Figs. 12, 16, and 15 by the skeletal mechanism M66. Values are in percent relative to the full model M560.

\begin{tabular}{llll}
\hline Species & M66 [\%] & Species & M66 [\%] \\
\hline $\mathrm{C}_{7} \mathrm{H}_{15}-1 /-2 /-3$ & $+61 /+44 /+32$ & $\mathrm{C}_{2} \mathrm{H}_{6}$ & +6 \\
$\mathrm{C}_{4} \mathrm{H}_{8}-1$ & +25 & $\mathrm{C}_{2} \mathrm{H}_{5}$ & -4 \\
$n-\mathrm{C}_{3} \mathrm{H}_{7}$ & +57 & $\mathrm{C}_{2} \mathrm{H}_{4}$ & +5 \\
$\mathrm{CH}_{3}$ & +2 & $\mathrm{C}_{2} \mathrm{H}_{3}$ & +1 \\
$\mathrm{CH}_{4}$ & +12 & $\mathrm{C}_{2} \mathrm{H}_{2}$ & +2 \\
$\mathrm{CH}_{3} \mathrm{O}$ & +79 & $\mathrm{C}_{3} \mathrm{H}_{6}$ & +12 \\
$\mathrm{CH}_{2} \mathrm{O}$ & +20 & $\mathrm{C}_{3} \mathrm{H}_{5}-\mathrm{a}$ & +11 \\
$\mathrm{HCO}$ & -3 & $\mathrm{C}_{3} \mathrm{H}_{4}-\mathrm{a} /-\mathrm{p}$ & $+20 /-42$ \\
$\mathrm{pC}_{4} \mathrm{H}_{9}$ & +41 & $\mathrm{C}_{3} \mathrm{H}_{3}$ & +12 \\
$\mathrm{HCCO}$ & +5 & $\mathrm{C}_{3} \mathrm{H}_{2}$ & +15 \\
$\mathrm{CO}$ & +1 & $\mathrm{CO}_{2}$ & +0 \\
$\mathrm{CH}_{2}$ & +2 & $\mathrm{CH}_{2}(\mathrm{~s})$ & +3 \\
$\mathrm{H}_{2}$ & +1 & $\mathrm{H}$ & -2 \\
$O$ & -4 & $\mathrm{OH}_{2}$ & +0 \\
$\mathrm{H}_{2} \mathrm{O}$ & +0 & $\mathrm{HO}_{2}$ & -2 \\
\hline
\end{tabular}




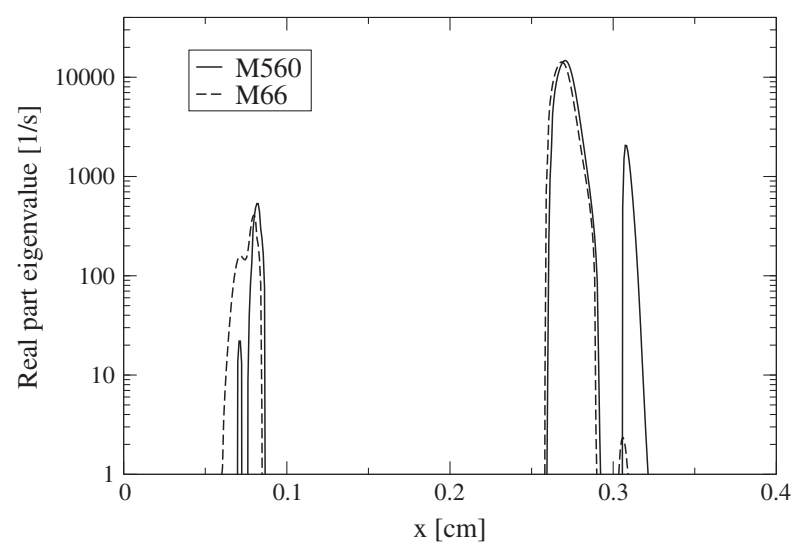

Fig. 20. Real part of the fastest explosive mode for the first horizontal cut through the triple flame $(y=0.2 \mathrm{~cm})$ using M560 and M66, see Fig. 17.

mechanisms M560 and M66 are small. The reactions of the base mechanism are mainly responsible for heat-release, therefore we find a good agreement in this respect.

To measure the propagation speed of the edge flame relative to the unburned gas we track a temperature isoline $(1000 \mathrm{~K})$ as a function of time. We only use a time interval in which the edge flame propagates at constant speed, i.e. we neglect the initial transients. We obtain the same propagation speed of $76 \mathrm{~cm} / \mathrm{s}$ for the two mechanisms M560 and M66. This is approximately $4 \mathrm{~cm} / \mathrm{s}$ faster than the propagation speed of the corresponding stoichiometric premixed flame.

It is also interesting to see if the structure of explosive modes found using the full mechanism M560 is reproduced by the skeletal mechanism. Figure 20 compares the eigenvalues of the fastest explosive mode for a horizontal cut through the flame at $y=0.2 \mathrm{~cm}$. We find a good agreement for the mode structure of the main explosive region in the rich premixed flame and mostly in the lean premixed flame. The explosive region on the low-temperature side of the rich premixed branch is almost completely missing in the case of the skeletal mechanism M66. As shown earlier, this region is dominated by the low-temperature ignition chemistry of $n$-heptane which was intentionally neglected in developing M66. The same conclusions can be drawn for a vertical cut through the triple flame along the stoichiometric line (not shown).

Overall, the skeletal mechanism M66 is found to be accurate in predicting the major flame properties - e.g. temperature, propagation speed, mole fractions of major reactants, products, and species of the methane base chemistry - at an approximately 72 fold reduced computational cost, see Table 2 . Low-temperature effects, as found for very lean or very rich premixed flames, are of minor importance in this edge flame. This is because the interactions between the different zones of the edge flame enhance the burning intensity of the premixed branches in relation to the small effects of low-temperature chemistry.

\subsection{Dependence on equivalence ratio in fuel stream}

We use the skeletal mechanism M66 to study the influence of the amount of fuel in the premixed, fuel-rich stream (flame B). The mixture composition at the inflow boundary is varied between pure air and about $\phi=10$ at the right-hand side which increases the amount of fuel and the mixture-fraction gradient in front of the edge flame, see Fig. 1 and Table 1 . All other parameters remain the same. We compare this computation to the calculation of flame A using the same mechanism M66.
The resulting heat-release rate, together with three isolines of mixture fraction, are shown in Fig. 21. The three isolines correspond to the equivalence ratios $0.5 / 1.0 / 2.5$ at the inflow boundary. The comparison with flame A, visually the same as Fig. 6, shows that the increased mixture-fraction gradient leads to a narrower flame structure with increased curvature. This large mixture-fraction gradient at the inflow is reduced significantly with $y$-distance up to the flame edge by diffusion and the velocity divergence before the flame tip. The lean and rich premixed branches can be identified even though they are much less pronounced and do not reach as far downstream as in flame A. Instead, the heat-release in the trailing diffusion flame downstream from the edge gains importance. The maximum heat-release rate at the tip of the edge flame is $20 \%$ smaller than for flame A (both calculated with M66).

A horizontal cut through flame B at $y=0.3 \mathrm{~cm}$ is shown in Fig. 22. For comparison, we also show the heat-release rate profile for a cut at $y=0.25 \mathrm{~cm}$ through flame A obtained with the same

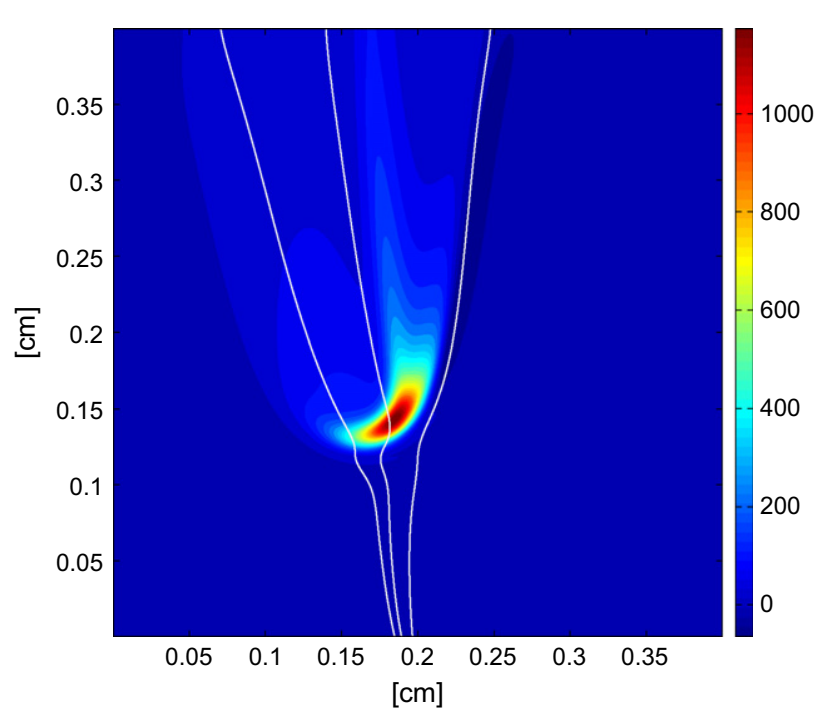

Fig. 21. Heat-release rate $\left[\mathrm{cal} / \mathrm{cm}^{3} \mathrm{~s}\right]$ for flame B and skeletal mechanism M66. Three isolines of mixture fraction are shown as well, corresponding to the stoichiometries $0.5,1.0$, and 2.5 at the inflow.

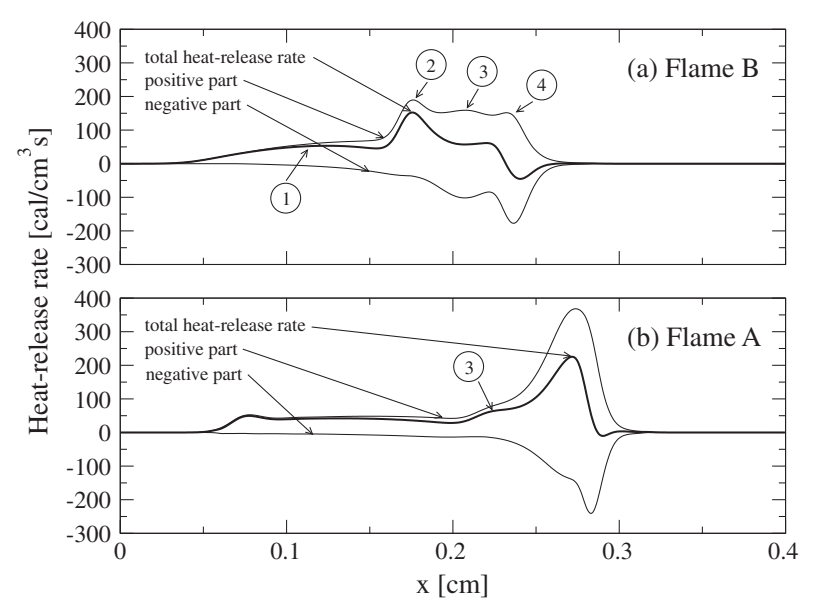

Fig. 22. Heat-release profiles along a horizontal cut (a) through $y=0.3 \mathrm{~cm}$ for flame $\mathrm{B}$ and (b) through $y=0.25 \mathrm{~cm}$ for flame A using the skeletal mechanism M66. The numbers denote points were the contribution of single reactions to the heat-release is analyzed, see text. 
mechanism M66. These two cuts are at the same distance downstream from the location of maximum heat-release rate.

The total heat-release rate resembles qualitatively the one we find for the one-dimensional opposed-jet configuration using pure air as oxidizer stream and a premixed fuel stream of $\phi \approx 5$ in the fuel stream, compare to Fig. 18. This shows that this cut through flame B is closer to the limit of a pure diffusion flame as compared to flame A.

The heat-release rate shows a broad peak on the lean side, the main peak slightly on the rich side of the stoichiometric mixture fraction, and a smaller peak on the rich side. In addition, there is an extended region with negative net heat-release. Compared to flame A, the small heat release peak in the lean branch is not present and the two peaks on the rich side are now well separated and swapped their importance. Moreover, the positive and negative contributions to the total heat-release show additional structure. Apart from the broad peak in the lean region (1), there are three distinct peaks of positive heat-release (2-4). Also the negative contribution shows three peaks.

A closer look at the individual reaction rates shows that essentially the same reactions as in flame A determine the heat-release. Instead of occurring in a small region around the premixed branch, heat-release is spread out in layers in this cut through flame B. The broad peak of heat-release rate (peak 1 ) is caused by $\mathrm{H}$ reacting with $\mathrm{O}_{2}$, the production of $\mathrm{H}_{2} \mathrm{O}$ from $\mathrm{H}$ and $\mathrm{OH}$, and the production of $\mathrm{CO}_{2}$ from $\mathrm{CO}$ and $\mathrm{OH}$. The main peak (2) is mainly caused by reactions involving $\mathrm{O}$ radicals and the subsequent reaction of HCCO:

$$
\begin{aligned}
\mathrm{CH}_{3}+\mathrm{O} & \rightarrow \mathrm{CH}_{2} \mathrm{O}+\mathrm{H} \\
\mathrm{C}_{2} \mathrm{H}_{2}+\mathrm{O} & \rightarrow \mathrm{CH}_{2}+\mathrm{CO} \\
& \rightarrow \mathrm{HCCO}+\mathrm{H} \rightarrow \mathrm{CH}_{2}(\mathrm{~s})+\mathrm{CO}
\end{aligned}
$$

These reactions contribute to peak 3 :

$$
\begin{aligned}
\mathrm{OH}+\mathrm{H}_{2} & \rightarrow \mathrm{H}+\mathrm{H}_{2} \mathrm{O} \\
\mathrm{C}_{3} \mathrm{H}_{3}+\mathrm{H} & \rightarrow \mathrm{C}_{3} \mathrm{H}_{2}+\mathrm{H}_{2} \\
\mathrm{CH}_{3}+\mathrm{H}+(\mathrm{M}) & \rightarrow \mathrm{CH}_{4}+(\mathrm{M})
\end{aligned}
$$

Finally, peak 4 reflects $\mathrm{C}_{3} \mathrm{H}_{6}$ being produced by $\mathrm{CH}_{3}$ and to a smaller extent the consumption of $\mathrm{C}_{3} \mathrm{H}_{5}$ :

$$
\begin{aligned}
\mathrm{CH}_{3}+\mathrm{CH}_{3}+(\mathrm{M}) & \rightarrow \mathrm{C}_{2} \mathrm{H}_{6}+(\mathrm{M}) \\
\mathrm{C}_{3} \mathrm{H}_{5}+\mathrm{H} & \rightarrow \mathrm{C}_{3} \mathrm{H}_{6}
\end{aligned}
$$

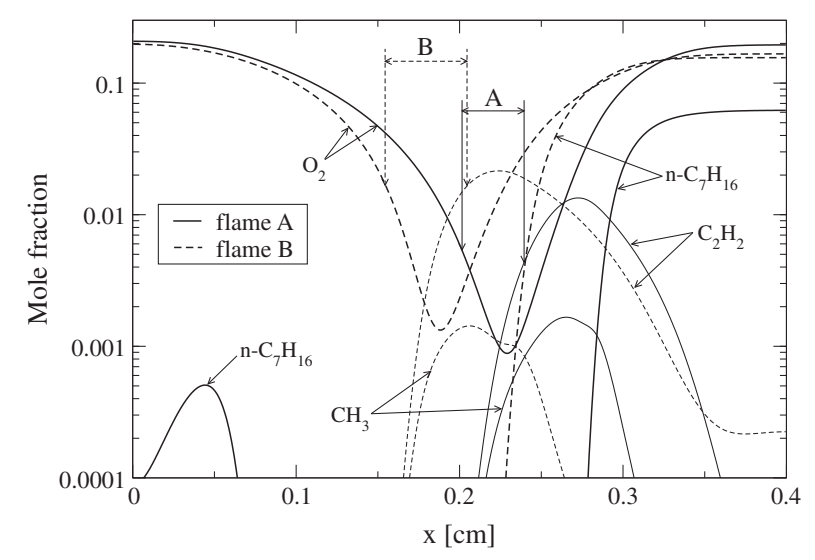

Fig. 23. Mole fractions of major carbon-containing species and $\mathrm{O}_{2}$ for a horizontal cut through flame A at $y=0.25 \mathrm{~cm}$ compared to a cut at $y=0.3 \mathrm{~cm}$ through flame B using M66. The cuts are $0.16 \mathrm{~cm}$ downstream from the point of maximum heatrelease rate in both cases. Arrows indicate the regions with significant heat-release of the trailing diffusion flame.
Figure 23 compares the mole fractions of the major species in both flames A and B for the same horizontal cuts as before. In both cases, the sequence and relative abundance of species originating from $n$ heptane are qualitatively the same. This is remarkable since flame A burns mainly as a rich premixed branch and flame B mostly as a diffusion flame. In case of flame A we still see the remains of the lean premixed branch on the left side of the domain. Arrows mark the regions behind the rich premixed branches where the distinct peak of heat-release occurs as part of the trailing diffusion flame, i.e. region 3 for flame A and region 2 in flame B, see Fig. 22. Because the rich premixed branch almost vanished in flame $B$ the mole fractions of important species are much larger in the region of the trailing diffusion flame, especially $\mathrm{C}_{2} \mathrm{H}_{2}$ and $\mathrm{CH}_{3}$. This leads to the pronounced heat-release in the trailing diffusion flame.

From a global perspective we find that flame $B$ is burning with a propagation speed of $60 \mathrm{~cm} / \mathrm{s}$ compared to $71.7 \mathrm{~cm} / \mathrm{s}$ for the stoichiometric, adiabatic flame. The edge flame is receding on the computational grid. This behavior is in agreement with theoretical predictions for edge flames having a curvature larger than a certain critical value, see for instance [4].

\section{Conclusions}

We presented the first in-depth analysis of the structure of a 2D $n$-heptane edge flame using detailed models for chemical reactions and transport properties. The dominant fuel-consumption pathways and processes of heat-release were examined in the different reaction zones behind the triple point. We found that the trailing diffusion flame has a two-layered structure fueled by $\mathrm{C}_{2} \mathrm{H}_{2}$ and $\mathrm{CH}_{3}$ on the rich side and $\mathrm{H}_{2}$ and $\mathrm{CO}$ on the lean side. The hydrocarbons with largest concentrations are the fuel, $\mathrm{CO}, \mathrm{CO}_{2}, \mathrm{C}_{2} \mathrm{H}_{4}$, and $\mathrm{C}_{2} \mathrm{H}_{2}$. We used CSP to identify dominant skeletal chemical kinetic models comprised of important elementary reaction pathways in different flame regions. We also used it to analyze the structure of explosive modes in the triple flame and found a dominant mode in the premixed flame branches associated with thermal runaway processes and a second mode in the low-temperature region ahead of the branches related to the low-temperature ignition chemistry of $n$-heptane.

By comparing cuts through the edge flame structure to corresponding one-dimensional premixed and partially-premixed flames we found qualitative similarities. Partially premixed counterflow flames proved to be valuable to understand qualitative features of the 2D edge flame.

Moreover we analyzed the accuracy of a skeletal mechanism for $n$-heptane combustion involving 66 species instead of 560 contained in the full model. It was developed using CSP from homogeneous ignition calculations neglecting the low-temperature chemistry. We found good agreement in the overall structure of the edge flame and its main properties: temperature, heat-release, and propagation speed. The species belonging to the $\mathrm{CH}_{4}$ base mechanism were found to be well predicted. Larger hydrocarbons showed significant deviations. Because the main flame properties were well reproduced, neglecting low-temperature ignition chemistry is not found to be important for these properties.

We also used the skeletal mechanism to study the change in structure of the edge flame when the amount of fuel in the partially-premixed fuel stream is increased. As expected, we find a flame structure closer to that of a non-premixed diffusion flame. The premixed branches are shorter, the maximum heat-release rate is decreased consistent with the increased curvature of the edge front. The propagation speed is found to be smaller than that of a stoichiometric premixed flame. A distinct heat-release structure of the diffusion flame can be found. This heat release is caused by the same reactions as in the computation with smaller 
equivalence ratio in the fuel stream, also the sequence and relative amounts of the main hydrocarbons is similar in the two edge flames. Since the rich premixed branch burns with a lower intensity, the concentrations of hydrocarbons reaching the diffusion flame is larger where they finally burn.

The present computation using the complete chemical mechanism for $n$-heptane can be used as a comprehensive dataset for the development of smaller, reduced mechanisms specific for application in edge flame computations. This dataset can also serve as a benchmark for other reduced mechanisms found in the literature.

\section{Acknowledgments}

This work was supported by the US Department of Energy (DOE), Office of Basic Energy Sciences (BES) Division of Chemical Sciences, Geosciences, and Biosciences. Sandia National Laboratories is a multiprogram laboratory operated by Sandia Corporation, a Lockheed Martin Company, for the United States Department of Energy under Contract No. DE-AC04-94-AL85000. MV acknowledges the support of the Italian Ministry of University and Research (MIUR). This research used resources of the National Energy Research Scientific Computing Center, which is supported by the Office of Science of the US Department of Energy under Contract No. DE-AC02-05CH11231.

\section{References}

[1] G. Amantini, J.H. Frank, M.D. Smooke, A. Gomez, Combust. Flame 147 (2006) 133-149.

[2] A.M. Briones, S. Som, S.K. Aggarwal, Combust. Flame 149 (2007) 448-462.

[3] J. Buckmaster, Prog. Energy Combust. Sci. 28 (2002) 435-475.

[4] S.H. Chung, Proc. Combust. Inst. 31 (2007) 877-892.

[5] G.R. Ruetsch, L. Vervisch, A. Liñán, Phys. Fluids 7 (1995) 1447-1454.

[6] T. Echekki, J.H. Chen, Combust. Flame 114 (1998) 231-245.

[7] R. Azzoni, S. Ratti, S.K. Aggarwal, I.K. Puri, Combust. Flame 119 (1999) 23-40.

[8] H.G. Im, J.H. Chen, Combust. Flame 119 (1999) 436-545.

[9] F. Takahashi, V.R. Katta, Proc. Combust. Inst. 29 (2002) 2509-2518.

[10] X. Qin, I.K. Puri, S.K. Aggarwal, Proc. Combust. Inst. 29 (2002) 1565-1572.

[11] X. Qin, C.W. Choi, A. Mukhopadhyay, I.K. Puri, S.K. Aggarwal, V.R. Katta, Combust. Theory Model. 8 (2004) 293-314.

[12] A.M. Briones, S.K. Aggarwal, V.R. Katta, Phys. Fluids 18 (2006) 043603.

[13] A.M. Briones, S.K. Aggarwal, V.R. Katta, Combust. Flame 153 (2008) 367-383.

[14] S.K. Choi, J. Kim, S.H. Chung, J.S. Kim, Combust. Theory Model. 13 (2009) 3956.

[15] B.A.V. Bennett, C.S. Mcenally, L.D. Pfefferle, M.D. Smooke, Combust. Flame 123 (2000) 522-546.

[16] F. Takahashi, V.R. Katta, Proc. Combust. Inst. 30 (2005) 375-382.

[17] V.R. Katta, W.M. Roquemore, 46th AIAA Aerospace Sciences Meeting and Exhibit AIAA 2008-1015, 2008.

[18] H.N. Najm, D. Ponganis, J. Prager, Proc. Combust. Inst. 32 (2009) 1117-1124

[19] H.N. Najm, M. Valorani, D.A. Goussis, J. Prager, Combust. Theory Model. 14 (2) (2010) 257-294.

[20] H. Xue, S.K. Aggarwal, AIAA J. 40 (11) (2002) 2289-2297.

[21] P. Berta, I.K. Puri, S.K. Aggarwal, Proc. Combust. Inst. 30 (2005) 447-453.

[22] P. Paul, J. Warnatz, Proc. Combust. Inst. 27 (1998) 495-504
[23] H.N. Najm, P.S. Wyckoff, O.M. Knio, J. Comp. Phys. 143 (1998) 381-402.

[24] O.M. Knio, H.N. Najm, P.S. Wyckoff, J. Comp. Phys. 154 (1999) 428-467.

[25] H.N. Najm, O.M. Knio, J. Sci. Comput. 25 (1-2) (2005) 263-287.

[26] H. Curran, P. Gaffuri, W. Pitz, C. Westbrook, Combust. Flame 129 (3) (2002) 253-280.

[27] H. Curran, P. Gaffuri, W. Pitz, C. Westbrook, Combust. Flame 114 (1-2) (1998) 149-177.

[28] M. Valorani, F. Creta, F. Donato, H.N. Najm, D.A. Goussis, in: P. Wesseling, E. Oñate, J. Périaux (Eds.), ECCOMAS CFD 2006, TU Delft, The Netherlands, 2006

[29] M. Valorani, F. Creta, F. Donato, H.N. Najm, D.A. Goussis, Proc. Combust. Inst. 31 (2007) 483-490.

[30] R. Bilger, S. Starner, R. Kee, Combust. Flame 80 (1990) 135-149.

[31] https://www.nersc.gov/nusers/systems/franklin/.

[32] J.J. Dongarra, C.B. Moler, J.R. Bunch, G.W. Stewart, LINPACK Users' Guide Society for Industrial and Applied Mathematics, Philadelphia, PA, 1979.

[33] P.N. Brown, G.D. Byrne, A.C. Hindmarsh, SIAM J. Sci. Stat. Comput. 10 (1989) $1038-1051$

[34] E. Anderson, Z. Bai, C. Bischof, S. Blackford, J. Demmel, J. Dongarra, J. Du Croz, A Greenbaum, S. Hammarling, A. McKenney, D. Sorensen, LAPACK Users' Guide, third ed., Society for Industrial and Applied Mathematics, Philadelphia, PA, 1999.

[35] M. Valorani, F. Creta, D.A. Goussis, J.C. Lee, H.N. Najm, Combust. Flame 146 (12) (2006) 29-51.

[36] N. Fenichel, J. Differ. Equations 31 (1979) 53-98.

[37] T.J. Kaper, in: J. Cronin, R.E. O'Malley Jr. (Eds.), Analyzing Multiscale Phenomena Using Singular Perturbation Methods, Proceedings of Symposia Applied Mathematics, vol. 56, AMS, Rhode Island, 1999, pp. 85-132.

[38] S.H. Lam, D.A. Goussis, Proc. Combust. Inst. 22 (1988) 931-941.

[39] S.H. Lam, D.A. Goussis, in: M.D. Smooke (Ed.), Reduced kinetic mechanisms and asymptotic approximations for methane-air flames, Lecture Notes in Physics, vol. 384, Springer, Berlin, 1991, pp. 227-242.

[40] S.H. Lam, Comb. Sci. Tech. 89 (1993) 375-404.

[41] S.H. Lam, D.A. Goussis, Int. J. Chem. Kinet. 26 (1994) 461-486

[42] D.A. Goussis, M. Valorani, J. Comp. Phys. 214 (2006) 316-346.

[43] M. Valorani, D.A. Goussis, F. Creta, H.N. Najm, J. Comp. Phys. 209 (2005) 754 786.

[44] M. Hadjinicolaou, D.A. Goussis, SIAM J. Sci. Comput. 20 (1998) 781-810.

[45] M. Valorani, H.N. Najm, D.A. Goussis, Combust. Flame 134 (2003) 35-53.

[46] D.A. Goussis, M. Valorani, F. Creta, H.N. Najm, Comput. Fluid Dyn. 6 (2005) 316-326.

[47] D.A. Goussis, H.N. Najm, SIAM Multiscale Model. Simul. 5 (2006) 1297-1332.

[48] J.C. Lee, H.N. Najm, S. Lefantzi, J. Raa, M. Frenklach, M. Valorani, D.A. Goussis, in: K.J. Bathe (Ed.), Computational Fluid and Solid Mechanics, Elsevier, Amsterdam, 2005, pp. 717-720.

[49] A. Kazakov, M. Chaos, Z. Zhao, F.L. Dryer, J. Phys. Chem. A 110 (2006) 7003 7009.

[50] T. Lu, C.S. Yoo, J.H. Chen, C.K. Law, 46th AIAA Aerospace Sciences Meeting and Exhibit AIAA 2008-1013, 2008.

[51] J. Prager, H.N. Najm, M. Valorani, D.A. Goussis, Proc. Combust. Inst. 32 (2009) 509-517.

[52] R.J. Kee, J.F. Grcar, M.D. Smooke, J.A. Miller, A Fortran program for modeling steady laminar one-dimensional premixed flames, Sandia Report SAND858240 UC-4, Sandia National Laboratories, 1985.

[53] H.R. Zhang, E.G. Eddings, A.F. Sarofim, C.K. Westbrook, Energy Fuels 21 (2007) 1967-1976.

[54] T.J. Held, A.J. Marchese, F.L. Dryer, Combust. Sci. Technol. 123 (1997) 107146.

[55] T. Lu, C.S. Yoo, J.H. Chen, C.K. Law, J. Fluid Mech. 652 (2010) 45-64.

[56] K.J. Hughes, T. Turányi, A.R. Clague, M.J. Pilling, Int. J. Chem. Kinet. 33 (2001) 513-538.

[57] J. Zádor, I.G. Zsély, T. Turányi, J. Phys. Chem. A 109 (2005) 9795-9807.

[58] I. Glassman, Combustion, third ed., Academic Press, San Diego, 1996. 581.

[59] A.E. Lutz, R.J. Kee, J.F. Grcar, F.M. Rupley, OPPDIF: a Fortran program for computing opposed-flow diffusion flames, Sandia Report SAND96-8243 UC1409, Sandia National Laboratories, 1997. 